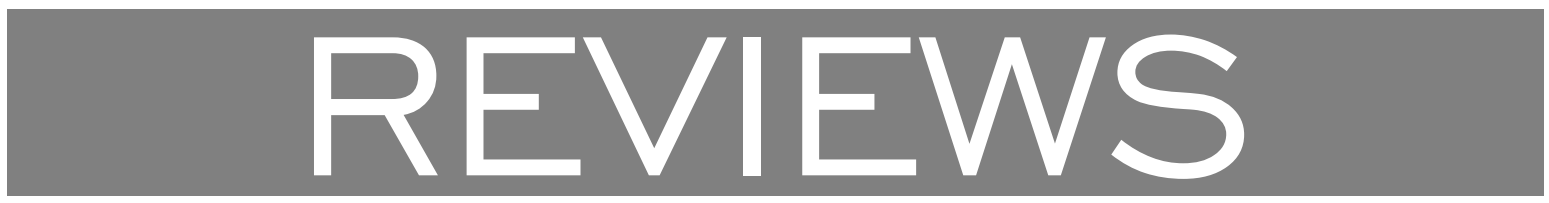

Ecological Monographs, 84(4), 2014, pp. 533-561

(C) 2014 by the Ecological Society of America

\title{
EcoVeg: a new approach to vegetation description and classification
}

\author{
Don Faber-Langendoen, ${ }^{1,11}$ Todd Keeler-Wolf, ${ }^{2}$ Del Meidinger, ${ }^{3,12}$ Dave Tart, ${ }^{4}$ Bruce Hoagland, ${ }^{5}$ Carmen \\ Josse, ${ }^{1}$ Gonzalo Navarro, ${ }^{6}$ Serguei Ponomarenko, ${ }^{7}$ Jean-Pierre Saucier, ${ }^{8}$ Alan Weakley, ${ }^{9}$ and Patrick Comer ${ }^{10}$ \\ ${ }^{1}$ NatureServe, Conservation Science Division, 4600 North Fairfax Drive, Arlington, Virginia 22203 USA \\ ${ }^{2}$ Biogeographic Data Branch, California Department of Fish and Game, Sacramento, California 95814 USA \\ ${ }^{3}$ British Columbia Ministry of Forests and Range, Research Branch, Victoria, British Columbia V8W 9 C2 Canada \\ ${ }^{4}$ USDA Forest Service, Intermountain Region, Natural Resources, Ogden, Utah 84401 USA \\ ${ }^{5}$ Oklahoma Biological Survey and Department of Geography, University of Oklahoma, Norman, Oklahoma 73019 USA \\ ${ }^{6}$ Universidad Católica Boliviana San Pablo, Unidad Académica Regional Cochabamba Departamento de Ciencias \\ Exactas e Ingenierias, Carrera de Ingeniería Ambiental, Cochabamba, Bolivia \\ ${ }^{7}$ Ecological Integrity Branch, Parks Canada, Rue Eddy, Gatineau, Quebec K1 A 0M5 Canada \\ ${ }^{8}$ Ministère des Ressources Naturelles 2700, Rue Einstein, Bureau B-1-185, Quebec City, Quebec G1P 3 W8 Canada \\ ${ }^{9}$ North Carolina Botanic Garden, University of North Carolina, Chapel Hill, North Carolina 27599 USA \\ ${ }^{10}$ NatureServe, 210855 th Street, Boulder, Colorado 80301 USA
}

Abstract. A vegetation classification approach is needed that can describe the diversity of terrestrial ecosystems and their transformations over large time frames, span the full range of spatial and geographic scales across the globe, and provide knowledge of reference conditions and current states of ecosystems required to make decisions about conservation and resource management. We summarize the scientific basis for EcoVeg, a physiognomic-floristic-ecological classification approach that applies to existing vegetation, both cultural (planted and dominated by human processes) and natural (spontaneously formed and dominated by nonhuman ecological processes). The classification is based on a set of vegetation criteria, including physiognomy (growth forms, structure) and floristics (compositional similarity and characteristic species combinations), in conjunction with ecological characteristics, including site factors, disturbance, bioclimate, and biogeography. For natural vegetation, the rationale for the upper levels (formation types) is based on the relation between global-scale vegetation patterns and macroclimate, hydrology, and substrate. The rationale for the middle levels is based on scaling from regional formations (divisions) to regional floristic-physiognomic types (macrogroup and group) that respond to meso-scale biogeographic, climatic, disturbance, and site factors. Finally, the lower levels (alliance and association) are defined by detailed floristic composition that responds to local to regional topo-edaphic and disturbance gradients. For cultural vegetation, the rationale is similar, but types are based on distinctive vegetation physiognomy and floristics that reflect human activities. The hierarchy provides a structure that organizes regional/ continental vegetation patterns in the context of global patterns. A formal nomenclature is provided, along with a descriptive template that provides the differentiating criteria for each type at all levels of the hierarchy. Formation types have been described for the globe; divisions and macrogroups for North America, Latin America and Africa; groups, alliances and associations for the United States, parts of Canada, Latin America and, in partnership with other classifications that share these levels, many other parts of the globe.

Key words: biogeography; Canadian National Vegetation Classification; cultural vegetation; ecosystem; floristics; growth form; International Vegetation Classification; natural vegetation; novel ecosystem; ruderal vegetation; U.S. National Vegetation Classification; vegetation type.

Manuscript received 19 December 2013; revised 5 March 2014; accepted 15 April 2014; final version received 12 May 2014. Corresponding Editor (ad hoc): N. Christensen.

${ }^{11}$ E-mail: don_faber-langendoen@natureserve.org

${ }^{12}$ Present address: Meidinger Ecological Consultants, 639 Vanalman Avenue, Victoria, British Columbia V8Z3A8 Canada.

\section{INTRODUCTION}

There never has been greater need than now to systematically inventory, classify, and map the incredible diversity of vegetation and ecosystems on Earth as land managers, conservationists, and policy makers are facing ever intensifying land uses and degraded land- 
scapes. The implications of global change for biodiversity, ecological processes, and ecosystem services are profound, even as historic natural systems are replaced by new or novel ecosystems. A paramount need for assessing these alterations is a system of vegetation classification that is operable at multiple spatial and temporal scales of resolution. Although vegetationbased classifications are often eschewed because of the heterogeneous and dynamic nature of vegetation, modelers of both climate and land-cover changes also recognize the merits of describing the dynamics of vegetation types (Leemans 1997, Williams et al. 2000, Mitchell 2005, Willis and Birks 2006, Beckage et al. 2008, Chiarucci et al. 2010, Williams and Baker 2011). In addition, ecologists and conservation scientists need real-time knowledge of ecosystem structure and composition in order to characterize reference conditions and natural disturbance dynamics across the landscape (Swetnam et al. 1999, Scott et al. 2002, Stoddard et al. 2006, Leu et al. 2008, Keene et al. 2009, Tierney et al. 2009, Thompson et al. 2013).

Vegetation ecologists acknowledge the need for more comprehensive systematic approaches to both vegetation survey and classification (e.g., Chytrý et al. 2011). Although vegetation classifications are a priority in many parts of the world, the systems devised cater to national or subcontinental interests and scale (e.g., Curtis 1959, Rodwell 1991-2000, Sawyer et al. 2009, Navarro 2011, Chytrý 2012), thereby limiting the need for the classifiers to account for the worldwide diversity of vegetation patterns. A globally applicable classification system is lacking.

We present a hierarchical classification that integrates biogeography, bioclimatology, and land-cover data into a scientifically based global vegetation classification for the interpretation of vegetation pattern at all scales. Our methodology, which we term the EcoVeg approach, provides a repeatable scientific system for the development and description of vegetation types. The goal is to systematically classify existing vegetation, reflecting both ecological and human processes and applicable from the global to local scale. While we do not argue that this is the only vegetation classification approach to use, we will show that it does address an important set of current needs and solves other classification shortcomings.

The EcoVeg approach builds on the traditional physiognomic-floristic-ecological classifications that have been developed over many years (e.g., Rübel 1930, as cited in Shimwell 1971, Whittaker 1962, Westhoff 1967, Webb et al. 1970, Beard 1973, Werger and Sprangers 1982, Borhidi 1991, Adam 1992). These classifications suggested ways in which multiple criteria for vegetation classification could be used to organize vegetation patterns along ecological lines. Common to these authors' perspectives is that both floristic and physiognomic units should be constructed in the context of ecological relationships. As Warming stated early in the last century (1909:142), "Why not use each growth form [lichen, moss, herb, dwarf-shrub, shrub, tree] as a foundation upon which to build a special class? The following classes could then be distinguished: that of forest formations, of bush-formations, of shrub-formations, of dwarf-shrub formations, of perennial-herb formations, of moss-formations, and of alga-formations ... from a morphological standpoint this would possess a certain interest, but from a phytogeographical one it must be dismissed, because it would involve the separation of formations that are oecologically closely allied." (Emphasis added.)

Similarly, Daubenmire (1968:252) observed that “... a 'needle-leaved coniferous forest' category would embrace the Pinus elliottii forests of Cuba, the Pinus ponderosa forests of Colorado, the Sequoia sempervirens forests of California, the Picea glauca forests of Yukon Territory, etc. Collectively these share nothing in common from the synecologic standpoint ... thus it is clear that physiognomy by itself lumps vegetation types that are vastly different in their ecological relations, and so results in an artificial classification. Then the opposite difficulty is illustrated by Warming's placement of salt marshes dominated by shrubby Salicornia in a different category from salt marshes dominated by herbaceous species of the same genus ... all this is not to deny that physiognomy can serve a useful purpose in defining major plant groupings, but it is useful only when ecologic and other considerations are allowed to govern its application."

Floristic approaches, such as those of Braun-Blanquet or Daubenmire, often give strong consideration to ecological relationships when assessing vegetation types (Westhoff and van der Maarel 1973:619). In fact, the historic association concept typically includes habitat conditions (Mueller-Dombois and Ellenberg 1974, Willner 2006, Jennings et al. 2009). Thus, both physiognomic and floristic characteristics can provide the biotic information needed for defining vegetation classification units, and the organization of their relationships can be assessed by their ecological, dynamic, and geographic (chorology) relevance (see also Pignatti et al. [1994]).

There are other vegetation characteristics that are still being explored for their role in vegetation classification. For example, inductive approaches to characterizing plant functional traits are now being gathered at the same scale as floristic data, such that classifications may benefit from considering these traits for classification (Box 1981, Cramer 1997, Gillison 2013). Although these fine-scale traits can be used to characterize environmentally adaptive aspects of plants, more research is needed to understand how they might be incorporated with physiognomic and floristic criteria for classification purposes. We note how information on functional traits could be used to extend our approach.

One of the challenges of a global classification is to provide guidance for type recognition across all scales. An accurate, concise definition for a global-scale 
tropical dry forest formation may be difficult, given the enormous diversity of tropical forests across the globe. Because the principles of the EcoVeg hierarchy ultimately bring global and local scales together, there is the opportunity for ongoing refinement and improvement of type definitions using both top-down and bottom-up methods (e.g., Miles et al. 2006).

No other global vegetation classification approach that we know of is based on an integration of physiognomy and floristics across all vegetation types at multiple scales. Perhaps the closest in scope to our approach is that of Di Gregorio and Jansen (1996), but theirs is a comprehensive descriptive method with multiple attributes organized around a few core categories. There are also a number of important continental or subcontinental physiognomic-floristic classifications, though they differ from our approach in a variety of ways, including in North America (Brown et al. 1979, Brown 1982), the former USSR (Komarov Botanical Institute; Aleksandrova 1973), in Australia (Specht et al. 1974, Specht and Specht 2001), in Europe, the physiognomic-floristic classification that guides the Natural Vegetation Map of Europe (Bohn et al. 20002003) and EUNIS (European Nature Information System; see Davies et al. [2004]), with its various predecessors (e.g., Devillers et al. 1991 [CORINE biotopes manual] and Devillers and Devillers-Terschuren 1996). Apart from Brown et al. (1979), the units and hierarchy neither attempt to represent global patterns of vegetation nor contain multiple scales of global to local types. We therefore developed the EcoVeg approach to address this need.

\section{Methods \\ Working group}

The classification approach presented here is the product of numerous efforts that began in the 1970s and 1980s to establish global ecological classification frameworks (see Grossman et al. [1998] for a brief overview of various physiognomic, floristic, and physiognomic-floristic approaches). At that time, any effort to develop a systematic vegetation classification in the United States had to first respond to challenges to community-unit concepts raised by continuum-based theories (Austin 1985), disenchantment with strongly floristic approaches based on the character species concepts of the Braun-Blanquet method (MuellerDombois and Ellenberg 1974:208-209), which led to a greater emphasis on the characteristic species combination (Chytrý and Tichý 2003), and a desire to explore more bio-geo-ecosystem approaches (Driscoll et al. 1984, Pojar et al. 1987, Bailey 1989a, Rowe and Barnes 1994). Concurrently, however, improvements in remote sensing technology and spatial modeling tools created a demand for a classification system that was consistent, repeatable, and operable at multiple spatial scales for characterization of vegetation-ecosystem patterns from both the ground and the air (Lowry et al. 2007).
In 2003, the Vegetation Subcommittee of the United States Federal Geographic Data Committee (FGDC 2008) sponsored the Hierarchy Revisions Working Group (HRWG) to address shortcomings in the UNESCO (1973) physiognomic-ecologic classification that formed the basis for the first iteration of the United States National Vegetation Classification (USNVC; see Grossman et al. [1998]). UNESCO (1973) was intended to facilitate global vegetation classification and mapping using remote sensing imagery. Because of an FGDC requisite that international standards for vegetation classification be considered during development of the USNVC, the HRWG was composed of vegetation ecologists from across the western hemisphere (see Appendix A for a list of members), and it sought peer review from international experts. The HRWG focused on the conceptual development of the upper and middle level units of the hierarchy to complement the lower level (alliance and association) units already put in place by Grossman et al. (1998). The FGDC (2008) and Jennings et al. (2009) provided guidance for the collection of vegetation field data from plots and for the description and analysis of lower level units of the classification, guidance that is relevant to the descriptions of all levels of the hierarchy presented here. They also provided a glossary of terms. A brief introduction to the USNVC was given in Faber-Langendoen et al. (2009), Franklin et al. (2012), and Kent (2012). An introduction and systematic description of the global formation types is provided in Faber-Langendoen et al. (2012).

The terrestrial vegetation focus of EcoVeg is based on assumptions that vegetation represents the majority of primary production of terrestrial ecosystems, is readily observable, and to a large degree integrates the biotic response to a variety of abiotic and disturbance factors at local, regional, and global scales. Thus, the approach adopts a bio-ecosystems (Walter 1985), as opposed to a geo-ecosystems (Rowe and Barnes 1994) approach, and is largely synonymous with the natural or ecological community concept used by a variety of state agencies and organizations within the United States (Grossman et al. 1998).

The conceptual development and description of EcoVeg units draws on important ecological products from bioclimatic (e.g., Holdridge 1947, Pojar et al. 1987, Rivas-Martínez 1996-2011, Metzger et al. 2012), biogeographic (e.g., Takhtajan 1986, Rivas-Martínez et al. 2011), and soils classifications (USDA 1999, Eswaran et al. 2003) to facilitate the understanding of vegetation patterns. In addition, the multiscale structure of the EcoVeg approach is compatible with existing land cover classifications that are utilized at national, continental, and global scales (see USGS National Land Cover Database [data available online]; ${ }^{13}$ Loveland et al. 1991,

\footnotetext{
${ }^{13}$ http://landcover.usgs.gov/natllandcover.php
} 
2000, Di Gregorio and Jansen 1996, USGS 2001, Bontemps et al. 2009, Fry et al. 2011).

\section{Methodological principles}

We contend that an operable vegetation classification scheme must have the capacity to describe existing vegetation patterns, including both cultural (planted and dominated by human processes) and natural (spontaneously formed and dominated by ecological processes, cf. van der Maarel 2005); describe vegetation types at multiple thematic scales, from thematically coarse formations (biomes) to fine-scale associations (biotopes); provide a readily interpretable inventory of vegetation and ecosystem patterns within and across landscape/ecoregional/watershed units; document status and trends of vegetation and ecosystems (e.g., trends in extent, such as range shifts, or trends in condition); facilitate interpretation of long-term (even paleoecological) change in vegetation with short-term change of existing vegetation, based on multiple vegetation criteria (growth forms, structure, floristics, etc.); and document the real-time shifts in ecosystem states caused by invasive species, land use, and climate change.

Based on these contentions, the EcoVeg approach contains nine core principles.

1) The classification is based on existing vegetation types, defined as the plant cover, including both floristic composition and vegetation structure, documented at a specific location and time, under specified ecological conditions, and preferably described at an optimal time during the growing season (Tart et al. 2005, FGDC 2008, Jennings et al. 2009). This is in contrast to potential vegetation concepts (Küchler 1964, Daubenmire 1968, Loidi and Fernández-González 2012), which rely on assumptions regarding vegetation successional stages, the presence of selected late successional plant species, and ecological species groups related to soils, topography, and climatic factors in the description of vegetation types. The two concepts are related in that mature examples of existing vegetation may represent expected states of potential vegetation types (Loidi and Fernández-González 2012).

2) Vegetation types are characterized by full floristic and growth form (physiognomic) composition, which together express ecological and biogeographical relations. Floristic data can provide joint species responses to environment and disturbance, both in the short and long term. These responses can be indicators of environmental change, disturbance regime shifts, and anthropogenic alterations. Growth forms reflect ecological and evolutionary pressures and processes; thus the composition of growth forms expresses both the long-term and immediate set of abiotic variables influencing vegetation structure (Whittaker 1975, Werger and Sprangers 1982, Adam 1992). For example, Box (1981) defined 90 plant growth-forms based on structural types (e.g., tree, shrub, etc.), leaf form (e.g., broad-leaved macrophyll), relative plant and leaf size, and seasonal activity pattern (e.g., summer green) for predictively mapping world biomes or vegetation formations. Thus, regional patterns of growth forms and species constitute distinctive patterns that can be used to define regional biomes, reflecting a long-term adjustment of vegetation to sites (Williams et al. 2000). At the same time, natural disturbances and human activities can rapidly alter the growth forms and species composition.

3) Vegetation characteristics are the product of natural and cultural processes. Cultural processes are human activities with purposeful, direct vegetation management objectives that produce distinct suites of species and growth forms (e.g., orchards, vineyards, row crops, gardens, forest plantations). Natural processes are ecologically driven and lead to more or less spontaneous vegetation patterns (Küchler 1969, Westhoff and van der Maarel 1973, Di Gregorio and Jansen 1996, van der Maarel 2005). See also Basic categories of the EcoVeg approach: Natural and cultural vegetation.

4) Characterizing and describing vegetation types is best accomplished using plot data, including both vegetation and other ecological data, which is collected and compiled using systematic protocols and survey techniques. Data management tools, including botanical databases, vegetation plot databases, and vegetation classification databases (Westhoff and van der Maarel 1973, Dengler et al. 2011, Peet et al. 2012), are essential for these activities.

5) Vegetation types can be defined using a number of differentiating criteria, including diagnostic, constant and dominant species, dominant and diagnostic growth forms, and compositional similarity. The most useful criteria are those that express ecological and biogeographical relationships and that clearly distinguish types (Warming 1909, Curtis 1959, Westhoff and van der Maarel 1973, Pignatti et al. 1994, Dierschke 1997, Willner 2006). These criteria should be defined for application in the field or lab, so that recognizable field characteristics are provided to ensure consistent identification using keys and other tools (De Cáceres and Wiser 2012). To that end, types are preferably defined as extensive concepts (the class concepts of Whittaker [1962:114-118]). Extensive concepts describe the full membership or range of variation of a type in relation to other types (e.g., as shown in Austin [2013: Fig. 3.4]), as compared to intensive or nodal concepts, where the membership or range of variation in the type is based on selected typical plots, but such variation may exclude intermediate plots. Intensive concepts may provide a first approximation of a type, which can be later expanded with increased knowledge of the type. There will always be 
difficulties in assigning stands to a type as one type transitions to another along a gradient, even when differentiating criteria are well understood.

6) Classification and field recognition of vegetation types is a distinct process that differs from vegetation mapping in that all vegetation maps are constrained by issues related to scale and technical limitations of mapping, which may restrict the ability of the map legend to show all vegetation types in a mapped area. Conversely, mapping units can describe spatial relationships among types not described by the classification (e.g., dry-dune-wet-swale type relationships). Because vegetation maps are often developed to study the geographic distribution, extent, and landscape patterns of vegetation, the linkages between recognizable field characteristics of vegetation classification and vegetation mapping should be established (Tart et al. 2005).

7) Differentiating criteria for vegetation types can be arranged hierarchically from upper levels primarily based on general growth forms to middle levels based on specific growth form and floristics that includes suites of general and regional combinations of characteristic species, and lower levels based primarily on regional to local floristics. At all levels, vegetation provides the primary criteria for descriptions within the hierarchy, but the organization may be based on the ecological and biogeographical relations expressed by the vegetation (Rübel 1930 as cited in Shimwell 1971, Whittaker 1962, Westhoff 1967, Pignatti et al. 1994, Brown et al. 1998).

8) An integrated hierarchy of vegetation types is best established by considering each level as both independent and interconnected in a nested relationship; that is, criteria selected to differentiate levels in the hierarchy are sufficient to define and distinguish types of a particular level, thereby preventing it from being arbitrarily defined by the level immediately above or below in the hierarchy. Thus, the EcoVeg method is both top-down and bottom-up. It is largely an inductive method, in so far as it rarely poses formal hypotheses, and the method of induction can be appropriately applied at any level (Mentis 1988). Opportunities for hypothesis testing (e.g., how relationships among vegetation types are established based on their physiognomy, floristics, and ecology) may emerge as the hierarchy is further developed.

9) A coordinating body should be established to oversee the recognition and integration of new classification units. A coordinating body is needed, given the more or less continuous nature of vegetation patterns and the potential for both multiple overlapping or uneven concepts. Even when such concepts are published, they may be difficult to reconcile with other independently published types. Proposed vegetation types, whether previously published or not, should undergo a peer review process specific to the classification standard conducted by a coordinating body. The coordinating body can review types published in independent publications to determine their relation to the standard set of vegetation types to ensure that all scientific contributions to the classification are considered, but the coordinating body provides the critical role of ensuring that published types are clearly distinguished from each other as much as possible. This assures that an authoritative version of the classification is maintained at all times, and it prevents potential confusion over duplication, overlap, and uneven scaling among types. A coordinated approach makes a standardized classification system readily available to practitioners, policy makers, and others (e.g., Rodwell 1991-2000, Grossman et al. 1998, Davies et al. 2004, Mucina and Rutherford 2006, Jennings et al. 2009).

These principles are essential when a consistent and comprehensive set of vegetation types is needed that are organized by vegetation and ecological relationships within a global framework. We encourage local or regional inventories and classifications to retain the core methodological principles $1-5$ on defining types, even if their classification hierarchy is structured differently, in order to permit linking these local and regional inventories with this global approach because these inventories are an important sources of information for any global classification effort.

\section{Related classification methods}

The philosophy guiding the EcoVeg methodology reflects, to varying degrees, the physiognomic-floristicecological systems noted in the Introduction (e.g., see Mueller-Dombois and Ellenberg [1974] for a general presentation of such systems). Those systems have typically not developed the kind of formal principles and methods presented here, so comparisons are difficult to make (but see the basic postulates of vegetation classification and mapping for southern Africa presented in Mucina and Rutherford [2006]). One system deserves special comparison: the Braun-Blanquet approach, as the HRWG learned much from it. Excellent summaries of that approach are available in Westhoff and van der Maarel (1973) and Dengler et al. (2008). First, both approaches share many aspects of principles 1-6. In particular, it is worth noting that principle 4, collecting plot-based (relevé) vegetation data for classification purposes, a core feature of the Braun-Blanquet approach, has become embedded in most formal vegetation classification approaches, including this one. But there also some noteworthy differences. The BraunBlanquet approach strongly emphasizes floristic-diagnostic features at all levels (cf. EcoVeg principle 2), restricts the scope of vegetation to natural and seminatural or spontaneous (not planted) vegetation (cf. EcoVeg principle 3), arranges the hierarchy based strongly on floristic-ecological criteria, with less empha- 
TABLE 1. Conceptual categories and level 1 of the hierarchy.

\begin{tabular}{|c|c|}
\hline Category and level 1 & Scientific name \\
\hline \multicolumn{2}{|l|}{ Vegetated } \\
\hline \multicolumn{2}{|l|}{ Natural vegetation } \\
\hline Forest and Woodland & Mesomorphic Tree Vegetation \\
\hline Shrub and Herb Vegetation & Mesomorphic Shrub and Herb Vegetation \\
\hline Desert and Semi-Desert & $\begin{array}{l}\text { Xeromorphic Woodland, Scrub and } \\
\text { Herb Vegetation }\end{array}$ \\
\hline Polar and High Montane Scrub and Grassland & Cryomorphic Vegetation \\
\hline Aquatic Vegetation & Hydromorphic Vegetation \\
\hline Open Rock Vegetation & Mesomorphic Vegetation \\
\hline \multicolumn{2}{|l|}{ Cultural vegetation } \\
\hline Agricultural and developed vegetation & Anthromorphic Vegetation \\
\hline Nonvegetated & excluded from classification, per se \\
\hline
\end{tabular}

sis on physiognomy (cf. EcoVeg principle 7), specifies one level, the association, as the fundamental unit, thereby placing other levels in a more dependent relation (cf. EcoVeg principle 8), and relies on the accumulation of literature-based, peer-reviewed publications to establish types, with no official coordinating body (cf. EcoVeg principle 9). Another difference is that the primary top Braun-Blanquet level, the class, contains many hundreds of units, e.g., 80 classes are reported for Europe alone by Rodwell et al. (2002), with no formal higher levels. In principle, the Braun-Blanquet method does have one higher level, division (Hadač 1967), but it is rarely used. The aggregation of classes is typically accomplished using ad hoc formations, but there has been no interest in the development of a formalized procedure for those units (Mucina 1997). This leaves the global patterns of vegetation unaccounted for by the Braun-Blanquet approach. Third, lack of specified class criteria for both physiognomy and floristics at the upper levels of the Braun-Blanquet approach has led to fewer range-wide standardized publications and applications, except through occasional synoptic publications. To some degree, the lack of systematic criteria for these units within Europe led to the creation of alternative European classifications, such as EUNIS (European Nature Information System). That system provides a comprehensive and specific set of criteria at the highest levels of the classification for all European vegetation (Davies et al. 2004), though revisions are under way to make it a more consistent framework (M. Chytrý, personal communication). Because of these differences, we believe the EcoVeg approach can better serve as a global vegetation classification framework.

Although there are other components of the BraunBlanquet system that bear further consideration (nomenclature, requirements for a type relevé when describing a new type, etc.), they are beyond the scope of this paper. Instead, we emphasize that there also is great compatibility between the two approaches, as is apparent in the natural vegetation map of Europe (Bohn et al. 2000-2003), which incorporates Braun-Blanquet types to describe European vegetation (Rodwell et al.
2002). We discuss these similarities when presenting the levels of the hierarchy.

\section{Basic Categories of the EcoVeg Approach}

We introduce two basic dichotomies that guide the overall hierarchy: the distinction between (1) vegetated and nonvegetated and (2) natural and cultural vegetation (cf. Di Gregorio and Jansen 1996). These categories explicitly demonstrate how the approach systematically classifies the enormous variation in terrestrial vegetation and how the classification units produced by the approach can be part of a larger set of categories that cover all ecosystems on the globe (freshwater, marine, subterranean; see Table 1).

\section{Vegetated and nonvegetated}

All terrestrial areas are classified as vegetated that have $\geq 1 \%$ surface coverage with live vascular and nonvascular plant species, including wetland vegetation (rooted emergent, submergent, and floating aquatic vegetation). For guidance on classifying nonvegetated terrestrial habitats, users should consult units provided by the Food and Agriculture Organization of the United Nations (FAO) Land Cover Classification System (Di Gregorio and Jansen 1996) and the United States National Land Cover Database (see footnote 13). For classifying freshwater and marine habitats, users should consult Cowardin et al. (1979), Higgins et al. (2005), and the Coastal and Marine Ecological Classification System (FGDC 2012), among others.

\section{Natural and cultural vegetation}

Although the term vegetation is often explicitly or implicitly (as in many texts that describe regional vegetation) restricted to natural vegetation (e.g., Westhoff and van der Maarel 1973, Barbour and Billings 2000, van der Maarel 2005), here we extend it to include cultural vegetation. The EcoVeg approach adopts this inclusive view because of the distinctive and evergrowing quantity of human-dominated/derived landcover types, whether cultural vegetation (Küchler 1969, Di Gregorio and Jansen 1996, Davies et al. 2004), 


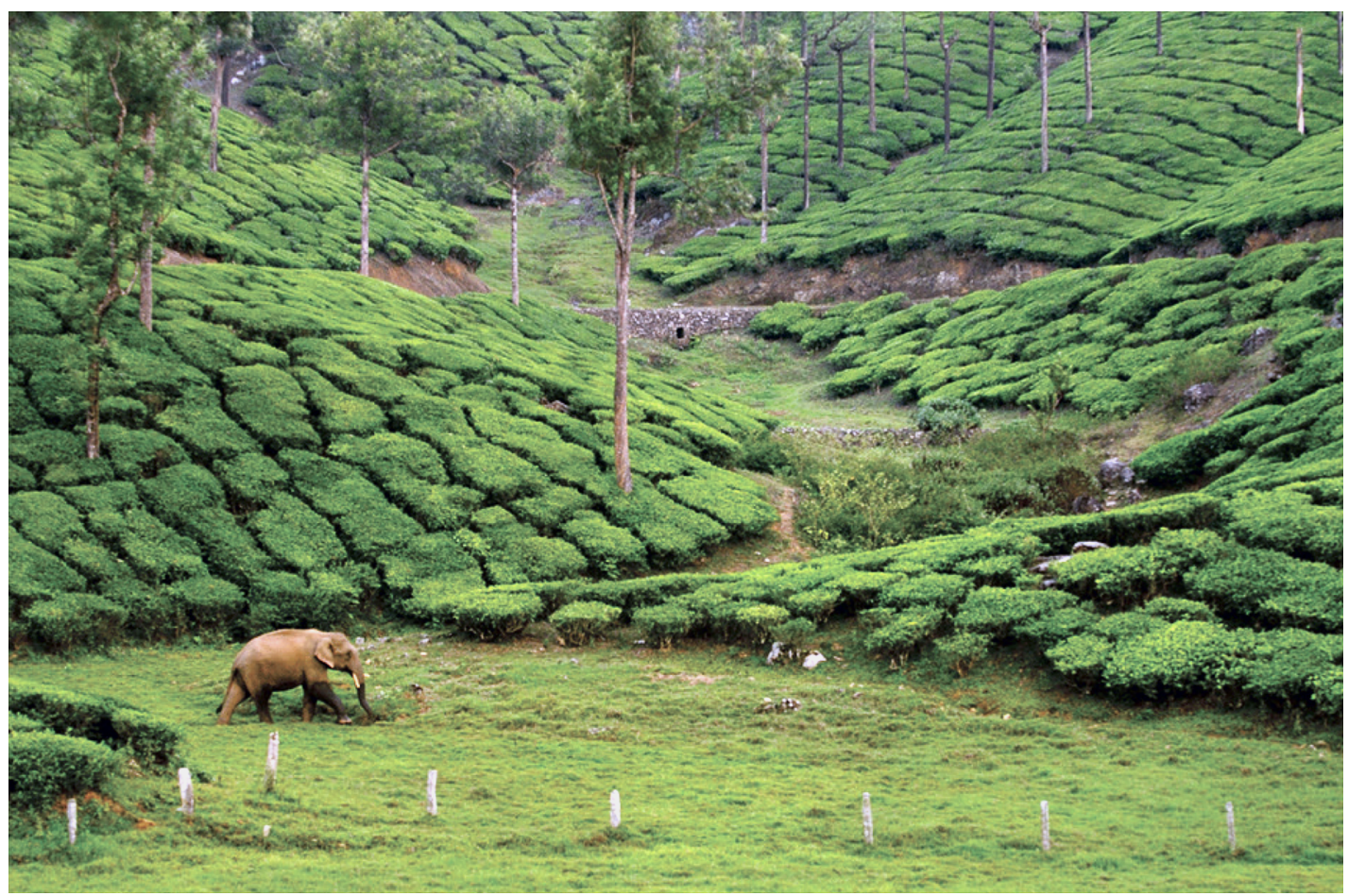

FIG. 1. Asian elephant passing through a tea plantation (cultural vegetation) in the Valparai plateau in Anamalai Hills of the western Ghats, India, on its way from one natural forest patch to another. Classifying the type of cultural vegetation is important to the overall assessment of elephant habitat because, although the elephants are able to use the tea plantations as part of a migratory corridor, they are also likely to run into conflict with humans as they pass through (Sukumar and Easa 2006). Photo Kalyan Varma. Used with permission.

cultural soils (i.e., the proposed Anthrosol order [Bryant and Galbraith 2003; International Committee for Anthropogenic Soils, available online]), ${ }^{14}$ or cultural biomes (Ellis and Ramankutty 2008). Describing cultural vegetation is also important within state and transition models that characterize the successional relationships among types on ecological sites (Bestelmeyer et al. 2004). Thus, including cultural vegetation in the EcoVeg approach is vital to characterizing the full range of variation in terrestrial ecosystems and in wildlife habitats (Di Gregorio and Jansen 1996). That variation will include challenging areas of transition between the two, such as sites where former industrial plantations have been partially cut and abandoned and acquire an increasingly native or naturalized flora, or where native grasslands are grazed and managed so intensively they take on many characteristics of seeded pastures. The roles of natural and cultural processes are not mutually exclusive. For example, although cultural vegetation can provide a degree of connectivity between natural habitats that wildlife depend on, knowledge of the type of cultural vegetation is important to understanding potential conflicts with human activities (Fig. 1). Thus, we incorporate human and natural processes into our high-level distinctions of types, recognizing that

\footnotetext{
${ }^{14}$ http://clic.cses.vt.edu/ICOMANTH
}

these influences form a continuum of human and ecological interactions.

Cultural vegetation possesses a distinctive structure and composition that is determined by the response to human intervention (cultural vegetation sensu stricto Küchler 1969, Di Gregorio and Jansen 1996). Characteristics of cultural vegetation are (1) regularly spaced herbaceous vegetation with substantial cover of bare soil for significant periods of the year (usually determined by tillage, chemical treatment, or agricultural flooding), (2) vegetation consisting of highly manipulated growth forms or structures rarely found under natural plant development (usually determined by mechanical pruning, mowing, clipping, etc.), and (3) vegetation composed of species not native to the area that have been intentionally introduced to the site by humans and that would not persist without active management by humans (e.g., arboretums).

Natural (including seminatural, ruderal, or weed) vegetation is composed predominantly of spontaneously growing sets of plant species with composition shaped by both abiotic (site) and biotic processes; these are vegetation types whose species composition is primarily determined by nonhuman ecological processes (Küchler 1969, Westhoff and van der Maarel 1973, van der Maarel 2005). Although natural vegetation is variously affected by human activities (e.g., logging, livestock 
grazing, fire, introduced pathogens), it retains a distinctive set of spontaneous vegetation and ecological characteristics (Westhoff and van der Maarel 1973, Di Gregorio and Jansen 1996).

Natural vegetation is sometimes restricted to historic, native vegetation or vegetation with analogs to potential natural vegetation (e.g., Barbour and Billings 2000, van der Maarel 2005). Here, we follow the Braun-Blanquet tradition and others in extending it to include the full range of natural vegetation from what Ellenberg (1988) called near-natural to seminatural. Thus, just as cultural vegetation is not devoid of some natural influences, so too within natural vegetation there is a range of both ecological and human processes affecting the vegetation. Ellenberg's near-natural vegetation of central Europe includes native, historic vegetation primarily shaped by ecological processes, such as the forests, wetlands, dunes, and alpine vegetation. His seminatural vegetation includes modified, ruderal, or weedy vegetation that had been moderately to substantially altered by anthropogenic disturbances, such as central European grasslands and dwarf-shrub heaths with relatively moderate human influences, as well as ruderal and weed communities found on heavily soil disturbed sites, and even the more intensively manipulated vegetation of forest plantations, hay, and litter meadows. Apart from our treatment of the more intensively manipulated vegetation as cultural vegetation, we agree with Ellenberg on the full scope of what is termed natural vegetation. We leave it to the classification process to determine how distinctive the vegetation may be as it relates to the varying degrees of human vs. ecological processes. Inclusion of both native and weedy vegetation within natural vegetation is perhaps akin to many botanical manuals that treat both native and naturalized species within their scope, but exclude the multitude of cultivated species found in lawns and farm fields.

That said, there has been growing interest in the more distinctive ruderal, invasive, and weedy vegetation types; that is, those with no apparent historical natural analogs, sometimes referred to as novel or emerging ecosystems (Hobbs et al. 2006, Belnap et al. 2012). These systems are often composed of invasive species, whether exotic or native, that have expanded in extent and abundance due to human disturbances, whether from abandonment of sites with cultural vegetation or from extensive alteration and degradation of more natural vegetation. For example, old fields in eastern North America that form on abandoned farm lands contain a mix of weedy natives and exotic shrubs, such as Rhamnus cathartica and Lonicera spp. (Wright and Fridley 2010). These fields have no analog to surrounding historic native vegetation in the regions. Similarly, vegetation that forms after tropical forests are cleared and burned may differ from any native vegetation in the area. For example, when sites with cerrado seasonally dry forest are extensively cleared and frequently burned, they may subsequently contain a floristically distinct derived savanna, comprised of invasive cogon grasses (Imperata cylindrica, Imperata brasiliensis) mixed with other weedy native and exotic grasses, herbs, and palms, rather than a natural cerrado savanna (Veldman and Putz 2011). In the southwestern United States and Mexico, a native invasive, Prosopsis glandulosa, expanded into more natural vegetation because of strongly altered fire and grazing regimes, leading to the formation of dense stands with an understory of Opuntia spp. and Bromus spp. (Belnap et al. 2012). P. glandulosa is also an exotic invader in parts of South African and Australia. These kinds of seminatural vegetation types reflect a fairly strong role of anthropogenic processes alongside successional ecological processes leading to a set of characteristic species with distinctive growth forms, ecology, and biogeography. For that reason, we add a ruderal label to the name of the type to indicate their placement in the classification (see Natural Vegetation: Hierarchy levels for natural vegetation: 3. Macrogroup and ruderal vegetation). We define ruderal vegetation as "vegetation found on human-disturbed sites, with no apparent recent historical natural analogs and whose current composition and structure is not a function of continuous cultivation by humans and includes a broadly distinctive characteristic species combination, whether tree, shrub, or herb dominated. The vegetation is often composed of invasive species, whether exotic or native, that have expanded in extent and abundance due to the human disturbances" (Curtis 1959, Ellenberg 1988, Lincoln et al. 1998). Our term is more restrictive than that of Grime (2001), who uses the term for any vegetation that forms after regular and severe disturbances, whether natural or human caused. By cataloguing these ruderal ecosystems, we seek to capture the full dynamics of existing vegetation on the landscape.

\section{Natural Vegetation}

\section{Criteria for the description of natural vegetation}

Growth forms and floristic characteristics that reflect ecological and biogeographical variables (Faber-Langendoen et al. 2009) are the primary properties of natural vegetation and are used to define all units of the hierarchy (cf. Mueller-Dombois and Ellenberg 1974). Further research is needed to determine whether the approach can be extended to include plant functional types (Gillison 2013).

Growth forms and structure.-Growth form criteria include (1) diagnostic combinations of growth forms, (2) dominant growth forms, singly or in combination, and (3) vertical and horizontal structure of growth forms. Growth forms are defined as the shape or appearance (physiognomy and structure) of a plant reflecting growing conditions and genetics (FGDC 2008). We use the term growth form in preference to life form, sensu Raunkier (1934), who defined forms into types based on environmental condition, specifically based on the position of the bud or perennating organ during the 
most unfavorable season. Growth forms describe a variety of types that reflect multiple ecological conditions. Growth forms are based on structural types (e.g., tree), leaf form (e.g., broad-leaved macrophyll), relative plant and leaf size, and seasonal activity pattern (e.g., summer green; see Mueller-Dombois and Ellenberg [1974], Whittaker [1975:359], Box [1981], Box and Fujiwara [2005], Mucina and Rutherford [2006: Table 2.1]). A growth form is usually consistent within a species, but may vary under extremes of environment.

The growth forms provided in Appendix B are a first approximation for defining upper level formation types (FGDC 2008) and for characterizing global vegetation patterns. The list consists of both general (Appendix B: Table B.1) and specific (Appendix B: Table B.2) growth forms. Morphological, anatomical, and physiological adaptations can be used to derive additional growth forms, but the use of species in combination with growth forms at middle levels of the hierarchy will alleviate this need. Nevertheless, the list in Appendix B can be amended to include, for example, the growth forms suggested by Box (1981) and Box and Fujiwara (2005) or some of the characteristics of plant functional types (e.g., the VegClass elements of Gillison 2013).

Because the growth forms used in the EcoVeg approach emphasize morphological adaptations, the suffix morphic is applied to vegetation types: hydromorphic, mesomorphic, xeromorphic (see also Ellenberg [1988: Table 4]). Although comparable to the use of hydrophyte, mesophyte, thermophyte, or xerophyte in other classification systems (e.g., Warming 1909, Rodwell et al. 2002, Huber and Riina 2003), we contend those terms are more aptly applied to species. In addition, the term hydrophyte in North America is applied to species occupying wetland habitats, irrespective of any obvious morphologic or anatomical adaptations. For example, Tiner (2006) defines hydrophytes as "plants growing in water or on a substrate that is at least periodically deficient in oxygen due to excessive wetness." By contrast, hydromorphic vegetation is defined by rooted and floating aquatic growth forms with anatomical features such as aerenchyma.

By identifying the growth forms on a site or in a vegetation plot, it is possible to empirically characterize the growth forms of a vegetation type and relate them to ecological factors. Thus, we can assess the diagnostic and dominant types of general growth forms that define a formation class, such as xeromorphic (desert) vegetation. At finer scales of formations, additional specific growth forms may be needed. For example, in distinguishing the tropical lowland rain forest from the tropical montane forest formation, Whitmore (1984: Table 18.1) noted differences in canopy height, leaf type, and flowering phenology among the growth forms of dominant trees, and he included a variety of minor diagnostic growth forms, such as vascular and nonvascular epiphytes and climbers. In other cases, growth forms, such as flowering forb, do not show particularly strong ecological relationships, at least not as currently defined, in which case, they may still be identified as constant growth forms (i.e., found in a high percentage of the plots sampled for a type, cf. Natural vegetation: Criteria for the description of natural vegetation: Floristics).

Growth forms also are closely related to plant functional types (PFTs), defined as a group of organisms with a shared response to environmental factors (Gitay and Noble 1997). For example, regeneration strategies of woody plant species subject to recurrent fire vary between regions, but many share the primary functional traits of resprouting following a crown fire and the retention of a viable postfire seed bank (Gillison 2013). The PFTs used for global-scale ecological assessments closely resemble the growth forms in the EcoVeg approach. Thus, PFTs can be concatenated with growth forms within a formation (Leemans 1997) for modeling the response of formations to disturbances and to climate change, following Box (1981), Cramer (1997) and Box and Fujiwara (2005).

In the EcoVeg approach, the following definitions are applied to growth forms.

Dominant growth form has a high percent cover (typically $>10 \%$ ), usually in the uppermost vegetation layer.

Diagnostic growth form is the presence, abundance, or vigor of growth forms that help differentiate one vegetation type from another. Diagnostic growth forms also reflect certain climatic and site conditions and can be identified using conceptual and analytical techniques, including their relation to global climatic factors (e.g., Cramer 1997, Box 2002, Wang et al. 2003).

Structural features, such as the canopy height of each vegetation stratum and canopy spacing, may be utilized for description of vegetation types. Cultural types (e.g., apple orchards) often differ fundamentally in both the growth form and the structural characteristic from natural types. Structural features may also serve a descriptive role within or between types, such as early, mid, or late seral forests, or open and closed shrublands.

Floristics.-Given that species are a fundamental unit of biodiversity, floristic composition is important in characterizing vegetation types. The definition of a vegetation type is summarized by characteristic species combinations, including (1) diagnostic combinations of species (character and differential species), (2) constant species, (3) dominant species, which reflect similar ecology and dynamic significance, and (4) vertical and horizontal structure of species. The terminology for characteristic species combinations largely follows the Braun-Blanquet tradition (Westhoff and van der Maarel 1973, Chytrý and Tichý 2003), with the inclusion of dominant species, which is also an expression of the dominant growth form. The characteristic species combination is considered a strong indicator of bioclimatic, biogeographic, geoedaphic, and successional conditions. We use the term species broadly to mean 
taxa, as the diagnostic value of taxa are occasionally made at the genus or subspecies level.

1. Diagnostic species.-Diagnostic species exhibit a relative constancy or abundance that clearly differentiates vegetation types and includes character and differential species (dominant and constant species may or may not be diagnostic).

Character species show a distinct maximum concentration, either in constancy and/or abundance, in one well-defined vegetation type, as compared to all others, and are recognizable at local, regional, and larger geographic scales (see Mueller-Dombois and Ellenberg [1974:178, 208], Bruelheide [2000]). Character species are often determined by comparison of vegetation types within the same physiognomic unit of a climatic or biogeographic region (Dengler et al. 2008).

Differential species are distinctly more widespread or abundant in a pair or closely related sets of plant communities than in the other(s), though they may still be more abundant in other communities not under consideration (Curtis 1959, Bruelheide 2000). The more limited a species is to one or a few plant community types under consideration, the stronger its differential value. Character species are a special case of differential species, since they differentiate a type from all other vegetation types, whereas differential species differentiate one closely related type from another (Dengler et al. 2008). In both cases, there is a "continuum in fidelity (diagnostic capacity) of species to vegetation types" (Chytrý and Tichý 2003, Chytrý 2007).

Constant species are present in a high percentage of the vegetation plots sampled to define a type. Threshold constancy values vary from lower to middle levels of the hierarchy because of increasing vegetation heterogeneity between levels, i.e., 40-60\% for association, $40 \%$ for alliance, and $25 \%$ for group and macrogroup (MuellerDombois and Ellenberg 1974, Chytrý and Tichý 2003, Chytrý 2007). The lower levels of constancy for midlevel types means that they are often defined by partially overlapping combinations of species. Constancy is influenced by plot size; thus, a fairly constrained range of plot sizes is recommended for vegetation studies (Dengler et al. 2009).

The term diagnostic species may overlap with the terms indicator species and ecological species groups ("species whose presence, abundance, or vigor is considered to indicate certain ecological conditions" [Gabriel and Talbot 1984]), particularly when the indicated ecological condition is known. In some classification methods, diagnostic species identified through data analysis receive more weight in determining a vegetation type, particularly when they have well understood relationships to specific environmental variables (soil moisture, soil $\mathrm{pH}$, nutrient regime, disturbance regime). However, diagnostic species may not always indicate a clear ecological relationship nor will all indicator species be diagnostic of a particular vegetation type.
Diagnostic species may be identified through analytical techniques, such as tabular sorting based on fidelity criteria (Westhoff and van der Maarel 1973), and numerical analyses, such as two-way indicator species analysis (e.g., Roleček et al. 2009), indicator value index (Dufrêne and Legendre 1997), phi coefficient (e.g., Chytrý et al. 2002), and hybrid approaches that optimize clustering for diagnostic species values (e.g., Tichý et al. 2010).

2. Dominant species.-Dominant species have the highest percent cover (the standard abundance measure for vegetation classification), biomass, or density. Species dominance is often assessed by strata, because taller statured species have greater volume or biomass. At the stand- or plot-level, the average cover of a dominant species is $>10 \%$, including codominant species. At the type-level, a dominant species is defined as a constant species with at least $10 \%$ average cover (adapted from Pojar et al. [1987]). In habitats where the vegetation is rather sparse, relative dominance may be a more helpful criterion.

Compositional similarity.-Compositional similarity is defined as a measure of the similarity in the presence and/or abundance of plant species between two or more plots or types. Numerical indices (e.g., Sorenson, BrayCurtis, Euclidean distance), ordination, and cluster analyses can be used to assess the degree of compositional similarity (Mueller-Dombois and Ellenberg 1974, Peet and Roberts 2013). At middle scales of vegetation pattern, where plots increasingly lack overlap in species composition but occupy similar ecological and biogeographical space, compositional similarity is assessed using suites of diagnostic species and growth forms related to biogeographic patterns (Pignatti et al. 1994).

Ecological context.-Criteria for ecological context include (1) biogeography (from large-scale biogeographic regions to regional biogeographic and biogeoclimatic zones), (2) climate (macro, meso, and microclimates), (3) disturbances (natural and cultural disturbances, and successional patterns), and (4) topo-edaphic factors, including the topographic features of elevation, slope, and aspect, as well as edaphic factors, such as $\mathrm{pH}$, moisture, nutrients, and texture.

Box and Fujiwara (2005) note the role of two ecological perspectives in interpreting vegetation patterns: "a historical-floristic perspective concerned with migration, dispersal and the historical development of regional floras; and the environmental perspective concerned with environmental constraints and ecological relations influencing distributions."

1. Biogeography.-Biogeography enters the hierarchy mostly at the middle levels to facilitate the identification of vegetation types that have very distinct floristic patterns. The province level of Takhtajan (1986) was very helpful for the EcoVeg approach, because it expresses the limited overlap in floristic composition between the dominant vegetation types across regions, and it accounts for the area affect (small provinces 
require more distinctive species than larger provinces). Thus, physiognomically based formation types that cross biogeographic provinces are typically distinct floristically, which points the way to division-level distinctions within the formation. The role of biogeography at lower levels (L6-L8) is less explicitly tied to biogeographic units per se; rather, greater emphasis is given to the interaction between ecological and biogeographic gradients.

2. Climate.-Climate is considered in all levels of the hierarchy. Macroclimate is used to describe vegetation types at the continental scale and is mostly independent of landform and vegetation (e.g., Köppen and Trewartha climate types, in Bailey [1996], macrobioclimates of Rivas-Martínez et al. [1999]). Mesoclimate (ecoregional climate) describes large geographic areas and is modified by continental position, landform, and elevation (Bailey 1989a, b, Ecoregions Working Group 1989). Mesoclimates are often inferred from vegetation formation patterns (Bailey 1996). Microclimate (or site climate) is modified by local topo-edaphic position.

The bioclimatic approach is helpful here because it describes the relationship between temperature and precipitation and the geographic distributions of species and ecosystems (e.g., Holdridge 1947, Thornthwaite 1948, Rivas-Martínez et al. 1999). The system of RivasMartínez et al. (1999) recognizes five macrobioclimates based on variation in rainfall, elevation and temperature, and bioclimate variants at the continental scale (tropical, mediterranean, temperate, boreal, and polar). These, along with the desert climate category of other eco-geographers (Walter 1985, Bailey 1989a, b, Schulz 1995) are reflected in the global formation types.

3. Disturbance regimes.-Disturbance regimes are used in descriptions at all levels of the hierarchy, from cultural or anthropogenic disturbances to flooding, fires, grazing, pathogen outbreaks, and windthrows. For our purposes, a disturbance occurs when the floristic or physiognomic characteristics of the vegetation are disrupted. Thus, disturbances may include both presence and absence of certain ecological or human processes that maintain a type. Disturbance regimes describe the types, frequency, severity, and size of disturbance on a given landscape and the interactions among disturbance types (Frelich 2002). The description of disturbance regimes is a function of the spatial and temporal scale of observation. In natural vegetation, humans have little to moderate influence on the frequency or severity of spontaneous ecological disturbance processes, whereas in cultural vegetation, humans largely determine the disturbance processes and those processes are tied to human activities.

4. Topo-edaphic factors.-Topo-edaphic factors are applied at mid to low levels of the hierarchy, but factors such as consolidated or unconsolidated rock, mountain ranges, peat, or other waterlogged soils can be utilized in the upper levels of the hierarchy. At finer scales, the relation of vegetation to topography and soils can be summarized by environmental gradients or a topoedaphic classification based on the primary gradients that determine vegetation patterns (e.g., moisture and nutrients, moisture and elevation; Curtis 1959, Whittaker 1975, Beckingham et al. 1996, Peet 2000).

\section{Hierarchy levels for natural vegetation}

The classification hierarchy consists of eight levels that are aggregated into three groupings: upper levels (L1-L3), middle levels (L4-L6), and lower levels (L7L8; see Table 2). The criteria outlined in Natural Vegetation: Criteria for the description of natural vegetation are used to develop descriptions of each unit in the hierarchy, but recall that the utility and relevance of the criteria vary with the level in the hierarchy. We provide the name, definition, and description for each level.

Upper levels (L1-L3).- The upper levels were developed based on the formation, a prominent concept throughout the history of vegetation classification (Shimwell 1971, Beard 1973, Mueller-Dombois and Ellenberg 1974, Faber-Langendoen et al. 2012). The formation as defined by UNESCO (1973) is "basically physiognomic-structural in character with supplementary ecological information integrated into its various categories and applicable to natural and semi-natural vegetation" and by Whittaker (1962:150) is "a community type defined by dominance of a given growth form in the uppermost stratum (or the uppermost closed stratum) of the community, or by a combination of dominant growth forms."

Formations are treated primarily as physiognomic units with descriptions based on ecological considerations. However, at the formation (L3) level, limited use of floristic (and biogeographic) descriptors from lower levels of the hierarchy can be applied. The comprehensive set of formation types for all three levels is provided in Appendix C. A detailed description of each formation type is available in Faber-Langendoen et al. (2012), along with guidance and comments over the precise boundaries of these classes. Practical applications of the classification suggest that clearly specified criteria for what constitutes forests and woodlands as compared to various grasslands and shrublands is important for conservationists, land managers, and policy makers. Here, we summarize the criteria for the three levels and compare them with the division level (Table 3).

1. Formation class (L1).-The formation class is "defined by broad combinations of dominant general growth forms adapted to basic moisture, temperature, and/or substrate or aquatic conditions" (FGDC 2008; cf. Beard 1973, cf. major physiognomic types of Whittaker [1975]). The formation class is the level at which users typically enter the classification; thus, a relatively small set of clearly defined types is helpful.

2. Formation subclass (L2).-The formation subclass is "defined by combinations of general dominant and diagnostic growth forms that reflect global macro- 
TABLE 2. Levels, definition, and example of the hierarchy for natural vegetation.

\begin{tabular}{|c|c|c|c|}
\hline \multirow[b]{2}{*}{ Natural hierarchy } & \multirow[b]{2}{*}{ Definition } & \multicolumn{2}{|c|}{ Example names } \\
\hline & & Scientific & Colloquial \\
\hline \multicolumn{4}{|l|}{ Upper levels } \\
\hline L1: Formation class & $\begin{array}{l}\text { A broad combination of dominant general } \\
\text { growth forms adapted to basic moisture, } \\
\text { temperature, and/or substrate or aquatic } \\
\text { conditions. }\end{array}$ & $\begin{array}{l}\text { Mesomorphic Shrub and } \\
\text { Herb Vegetation }\end{array}$ & $\begin{array}{l}\text { Shrub and Herb } \\
\text { Vegetation }\end{array}$ \\
\hline L2: Formation subclass & $\begin{array}{l}\text { A combination of general dominant and } \\
\text { diagnostic growth forms that reflect global } \\
\text { mega- or macroclimatic factors driven } \\
\text { primarily by latitude and continental } \\
\text { position or that reflect overriding substrate } \\
\text { or aquatic conditions. }\end{array}$ & $\begin{array}{l}\text { Temperate and Boreal } \\
\text { Shrub and Herb } \\
\text { Vegetation }\end{array}$ & $\begin{array}{l}\text { Temperate and } \\
\text { Boreal Grassland } \\
\text { and Shrubland }\end{array}$ \\
\hline L3: Formation & $\begin{array}{l}\text { A combination of dominant and diagnostic } \\
\text { growth forms that reflect global } \\
\text { macroclimatic conditions as modified by } \\
\text { altitude, seasonality of precipitation, } \\
\text { substrates, and hydrologic conditions. }\end{array}$ & $\begin{array}{l}\text { Temperate Shrub and Herb } \\
\text { Vegetation }\end{array}$ & $\begin{array}{l}\text { Temperate } \\
\text { Grassland and } \\
\text { Shrubland }\end{array}$ \\
\hline \multicolumn{4}{|l|}{ Mid levels } \\
\hline L4: Division & $\begin{array}{l}\text { A combination of dominant and diagnostic } \\
\text { growth forms and a broad set of diagnostic } \\
\text { plant species that reflect biogeographic } \\
\text { differences in composition and continental } \\
\text { differences in mesoclimate, geology, } \\
\text { substrates, hydrology, and disturbance } \\
\text { regimes. }\end{array}$ & $\begin{array}{l}\text { Andropogon-Stipa- } \\
\text { Bouteloua Grassland and } \\
\text { Shrubland }\end{array}$ & $\begin{array}{l}\text { Great Plains } \\
\text { Grassland and } \\
\text { Shrubland }\end{array}$ \\
\hline L5: Macrogroup & $\begin{array}{l}\text { A moderate set of diagnostic plant species and } \\
\text { diagnostic growth forms that reflect } \\
\text { biogeographic differences in composition } \\
\text { and subcontinental to regional differences in } \\
\text { mesoclimate, geology, substrates, hydrology, } \\
\text { and disturbance regimes. }\end{array}$ & $\begin{array}{l}\text { Andropogon gerardii- } \\
\text { Schizachyrium } \\
\text { scoparium-Sorghastrum } \\
\text { nutans } \text { Grassland and } \\
\text { Shrubland }\end{array}$ & $\begin{array}{l}\text { Great Plains } \\
\text { Tallgrass Prairie }\end{array}$ \\
\hline L6: Group & $\begin{array}{l}\text { A relatively narrow set of diagnostic plant } \\
\text { species (including dominants and } \\
\text { codominants), broadly similar composition, } \\
\text { and diagnostic growth forms that reflect } \\
\text { regional mesoclimate, geology, substrates, } \\
\text { hydrology, and disturbance regimes. }\end{array}$ & $\begin{array}{l}\text { Andropogon gerardii- } \\
\text { Heterostipa spartea- } \\
\text { Muhlenbergia } \\
\text { richardsonis Grassland }\end{array}$ & $\begin{array}{l}\text { Northern Great } \\
\text { Plains Tallgrass } \\
\text { Prairie }\end{array}$ \\
\hline \multicolumn{4}{|l|}{ Lower levels } \\
\hline L7: Alliance & $\begin{array}{l}\text { A characteristic range of species composition, } \\
\text { habitat conditions, physiognomy, and } \\
\text { diagnostic species, typically at least one of } \\
\text { which is found in the uppermost or } \\
\text { dominant stratum of the vegetation. } \\
\text { Alliances reflect regional to subregional } \\
\text { climate, substrates, hydrology, moisture/ } \\
\text { nutrient factors, and disturbance regimes. }\end{array}$ & $\begin{array}{l}\text { Andropogon gerardii- } \\
\text { Sporobolus heterolepis } \\
\text { Grassland }\end{array}$ & $\begin{array}{l}\text { Northern Mesic } \\
\text { Tallgrass Prairie }\end{array}$ \\
\hline L8: Association & $\begin{array}{l}\text { A characteristic range of species composition, } \\
\text { diagnostic species occurrence, habitat } \\
\text { conditions, and physiognomy. Associations } \\
\text { reflect topo-edaphic climate, substrates, } \\
\text { hydrology, and disturbance regimes. }\end{array}$ & $\begin{array}{l}\text { Andropogon gerardii- } \\
\text { Heterostipa spartea- } \\
\text { Sporobolus heterolepis } \\
\text { Grassland }\end{array}$ & $\begin{array}{c}\text { Northern Mesic Big } \\
\text { Bluestem Prairie }\end{array}$ \\
\hline
\end{tabular}

Note: The name of the level can be added to the type name for clarity, where needed.

climatic factors driven primarily by latitude and continental position, or that reflect overriding substrate or aquatic conditions" (FGDC 2008; cf. Whittaker 1975). Macroclimatic factors largely determine vegetation patterns.

3. Formation (L3).--Formation is "defined by combinations of dominant and diagnostic growth forms that reflect global macroclimatic conditions as modified by altitude, seasonality of precipitation, substrates, and hydrologic conditions" (FGDC 2008; cf. formation-type and biome-type of Whittaker [1975], Lincoln et al. [1998]). Here the vegetation patterns typically reflect the combination of major climates and substrate and topography.

4. Other applications of the formation concept.-A number of physiognomic or formation systems (Whittaker 1975, Brown et al. 1998, NLWRA 2001, Olson et al. 2001, Specht and Specht 2001, Rodwell et al. 2002) were reviewed when developing the EcoVeg approach (Appendix D). Most of these classification systems 
TABLE 3. Interpretive guidelines for vegetation and ecologic criteria for upper formation levels.

\begin{tabular}{|c|c|c|c|c|}
\hline \multirow[b]{2}{*}{ Guideline } & \multicolumn{4}{|c|}{ Level } \\
\hline & Formation class & Formation subclass & Formation & Division \\
\hline Growth forms & $\begin{array}{l}\text { Broad combinations of } \\
\text { dominant general } \\
\text { growth forms and } \\
\text { specific growth } \\
\text { forms. Overlapping } \\
\text { general growth forms } \\
\text { (e.g., shrub, herb), } \\
\text { but combinations of } \\
\text { diagnostic growth } \\
\text { forms generally } \\
\text { nonoverlapping (e.g., } \\
\text { xeromorphic forms in } \\
\text { desert vegetation). }\end{array}$ & $\begin{array}{l}\text { Combinations of } \\
\text { general and specific } \\
\text { dominant and } \\
\text { diagnostic growth } \\
\text { forms. Some growth } \\
\text { forms partially } \\
\text { nonoverlapping } \\
\text { among subclasses } \\
\text { (e.g., broadleaf } \\
\text { evergreen trees in } \\
\text { warm temperate } \\
\text { forests and tropical } \\
\text { forests). }\end{array}$ & $\begin{array}{l}\text { Combinations of } \\
\text { dominant and } \\
\text { diagnostic growth } \\
\text { forms based on either } \\
\text { individual diagnostic } \\
\text { growth forms (e.g., } \\
\text { mangrove, seagrass } \\
\text { beds), or } \\
\text { combinations (e.g., } \\
\text { warm temperate } \\
\text { sclerophyll evergreen } \\
\text { broadleaf, cool } \\
\text { temperate broad-leaf } \\
\text { cold-deciduous). } \\
\text { Relative abundances } \\
\text { in relation to } \\
\text { ecological factors } \\
\text { important. }\end{array}$ & $\begin{array}{l}\text { Broadly uniform sets of } \\
\text { growth forms and } \\
\text { canopy closure (same } \\
\text { as formation, but } \\
\text { variant expressions; } \\
\text { e.g., conifer- } \\
\text { dominated Rocky } \\
\text { Mountain forest } \\
\text { division, compared to } \\
\text { broadleaf deciduous } \\
\text { hardwood dominated } \\
\text { Eastern North } \\
\text { American forest } \\
\text { division). Essentially } \\
\text { nonoverlapping } \\
\text { floristics. }\end{array}$ \\
\hline $\begin{array}{l}\text { Ecological factors } \\
\text { (climate, distur- } \\
\text { bance, and edaphic/ } \\
\text { hydrology) }\end{array}$ & $\begin{array}{l}\text { Basic moisture, } \\
\text { temperature, and/or } \\
\text { substrate or aquatic } \\
\text { conditions. }\end{array}$ & $\begin{array}{l}\text { Global macroclimatic } \\
\text { factors driven } \\
\text { primarily by latitude } \\
\text { and continental } \\
\text { position, or that } \\
\text { reflect overriding } \\
\text { substrate or aquatic } \\
\text { conditions. }\end{array}$ & $\begin{array}{l}\text { Global macroclimatic } \\
\text { conditions as } \\
\text { modified by altitude, } \\
\text { seasonality of } \\
\text { precipitation, } \\
\text { substrates, and } \\
\text { hydrologic } \\
\text { conditions. }\end{array}$ & $\begin{array}{l}\text { Continental } \\
\text { macroclimate } \\
\text { separates formations } \\
\text { by continental or } \\
\text { major inter- } \\
\text { continental climatic } \\
\text { patterns. Broad range } \\
\text { of conditions } \\
\text { consistent with } \\
\text { continental } \\
\text { expression of } \\
\text { formation (e.g., the } \\
\text { division spans } \\
\text { floodplain and } \\
\text { swamp conditions). } \\
\text { Divisions within a } \\
\text { formation are often } \\
\text { geographically } \\
\text { separated. }\end{array}$ \\
\hline Diagnostic species & & & & $\begin{array}{l}\text { One or more sets of } \\
\text { strongly diagnostic } \\
\text { (character) species } \\
\text { among the diagnostic } \\
\text { species; species have } \\
\text { high fidelity but } \\
\text { variable constancy. }\end{array}$ \\
\hline
\end{tabular}

Notes: The division level is included for comparison. Empty cells signify no data possible. See also Table 4.

develop a large set of general physiognomic units within one or two levels (about 40 world formation units) rather than having multiple physiognomic levels. Similarly, the EcoVeg formation units are based on multiple criteria at each level, reflecting global-scale ecological factors rather than a single major vegetation criterion at each level (Faber-Langendoen et al. 2012). The objective was to ensure that the EcoVeg formations were truly global in scope and contained a range of growth forms (Appendix B) that together reflected major ecological factors.

Middle level units (L4-L6).- - The middle level units are based on regional species pools that have been sorted through biogeographic and ecological drivers (regional climate, topo-edaphic factors, and geologic substrates) of species composition and growth forms. EcoVeg can take a bottom-up approach to classification, which results in the resolution of floristic affinities at middle levels. Nevertheless, as noted in Methods: Methodological principles, middle-level types and descriptions can be drafted independently of or prior to the establishment of units lower in the hierarchy, drawing on the large body of knowledge on the response of species and growth forms to regional ecological factors. Thus, the biogeographical and ecological relationships structuring vegetation patterns can be described within the regionally scaled level of the division (regional formation) and the finely scaled alliances and associations. Criteria for the development of middle-level descriptions are summarized in Table 4.

1. Division (L4).-Division is defined as "combinations of dominant and diagnostic growth forms and a broad set of diagnostic plant species that reflect biogeographic differences in composition and continen- 
TABLE 4. Interpretive guidelines for vegetation and ecology criteria, from division to association.

\begin{tabular}{llc}
\hline \hline \multirow{2}{*}{ Guideline } & \multicolumn{1}{c}{ Level } \\
\cline { 2 - 3 } Definition (FGDC 2008) & \multicolumn{1}{c}{ Division } & \multicolumn{1}{c}{ Macrogroup } \\
\cline { 2 - 3 } & $\begin{array}{c}\text { A vegetation unit with broadly uniform } \\
\text { growth forms and a broad set of } \\
\text { diagnostic plant species at large } \\
\text { biogeographic scales that reflect } \\
\text { continental distinctions in climate, } \\
\text { geology, substrates, hydrology, and } \\
\text { disturbance regimes. }\end{array}$ & $\begin{array}{c}\text { A vegetation unit that contains moderate } \\
\text { sets of diagnostic plant species and } \\
\text { diagnostic growth forms that reflect } \\
\text { subcontinental to regional biogeographic } \\
\text { composition and subcontinental to }\end{array}$ \\
& regional mesoclimate, geology, substrates, \\
& hydrology, and disturbance regimes.
\end{tabular}

Biogeography/floristics

Diagnostic species

Growth forms

Climate

Disturbance regime/succession

Edaphic/hydrology
Large scale, continental, biogeography with largely nonoverlapping floristics (i.e., most species ranges fully contained), species heterogeneity high. Global formations separated by continental-intercontinental patterns of species into divisions.

A large suite of strongly diagnostic species (large number of character species among the diagnostic species; species have high fidelity but variable constancy).

Broadly uniform sets of growth forms and canopy closure (same as formation level, but variant expressions; e.g., coniferdominated Rocky Mountain forest division vs. broad-leaf deciduous hardwood forests of Eastern North American forest division).

Continental macroclimate. Separates formations by continental or major intercontinental climatic patterns.

Variable range of disturbance regimes consistent with continental expression of formation.

Broad range of conditions consistent with continental expression of formation (e.g. the divisions span floodplain and swamp conditions).
Subcontinental to regional ecological gradient segment (often mesoclimatic), reflected by sets of strongly diagnostic species (many species ranges fully contained); overall composition very distinct from other units.

Multiple sets of strong diagnostic species, including many strong differential and character species. Constant species become more important; at least $25 \%$ constancy expected.

Broadly uniform sets of growth forms and canopy closure. May be specific growth form variants that support floristic patterns, e.g., herb vs. shrub, coastal softleaved chaparral vs. inland sclerophyll chaparral.

Subcontinental mesoclimate. Indicative of primary regional gradients in vegetation, e.g., latitudinal, altitudinal, continentality (major zonal or strong azonal gradients).

Broadly consistent, but variable disturbance regimes indicative of subcontinental climate (e.g., floods, large-scale fires).

Broad range of conditions, sometimes reflective of broad topo-edaphic interactions with climate (e.g., large-scale droughty soils with or without fires) or broad-scale specialized geological substrates.

Notes: These are typical criteria, and the role of factors may differ for some types. The role of ecological factors at each level may also differ depending on the site conditions, e.g., at the macrogroup and group levels, the substrate factors on atypical or azonal wet or dry sites may more strongly influence on vegetation patterns than do mesoclimates, which may more strongly influence vegetation on typical or zonal or characteristic mesic upland sites. See also Table 3.

tal differences in mesoclimate, geology, substrates, hydrology, and disturbance regimes" (FGDC 2008). Whereas the formation level (L3) is more strictly physiognomic, the division level includes both physiognomic and floristic criteria. The term division was adopted from the Braun-Blanquet approach, which proposed it as a level above the class (Hadač 1967, Westhoff and van der Maarel 1973, Pignatti et al. 1994). For example, Westhoff and van der Maarel (1973:665) define the division as follows:

"A [vegetation type] above the class level that unites related classes within a floristic region (or province) on the basis of common division character-taxa. The character taxa may be species, or genera or both ... the definition of the division is not physiognomic. We suggest that, the difference in definition notwithstanding, divisions may converge in practice with the formations of the Anglo-American ecology as broad physiognomic units limited to a given region or continent."

As the EcoVeg approach explicitly defines the division using both physiognomic and floristic criteria, it should largely be compatible with their definition of division.

The term division is sometimes referred to as a regional formation (Richards 1952, Beard 1973, Whittaker 1975). For example, Richards divides his tropical rain forest-type into the American rain-forest formation, African rain-forest formation, and the Indo-Malayan 
TABLE 4. Extended

\begin{tabular}{|c|c|c|}
\hline \multicolumn{3}{|c|}{ Level } \\
\hline Group & Alliance & Association \\
\hline $\begin{array}{l}\text { A vegetation unit that is defined by a } \\
\text { relatively small set of diagnostic } \\
\text { plant species (including dominants } \\
\text { and codominants), broadly similar } \\
\text { composition, and diagnostic growth } \\
\text { forms that reflect regional } \\
\text { mesoclimate, geology, substrates, } \\
\text { hydrology, and disturbance regimes. }\end{array}$ & $\begin{array}{l}\text { A vegetation classification unit containing } \\
\text { one or more associations and defined by a } \\
\text { characteristic range of species composition, } \\
\text { habitat conditions, physiognomy, and } \\
\text { diagnostic species, typically at least one of } \\
\text { which is found in the uppermost or } \\
\text { dominant stratum of the vegetation. } \\
\text { Alliances reflect regional to subregional } \\
\text { climate, substrates, hydrology, moisture/ } \\
\text { nutrient factors, and disturbance regimes. }\end{array}$ & $\begin{array}{l}\text { A vegetation classification unit defined } \\
\text { on the basis of a characteristic range } \\
\text { of species composition, diagnostic } \\
\text { species occurrence, habitat conditions } \\
\text { and physiognomy. Associations } \\
\text { reflect subregional to local topo- } \\
\text { edaphic factors of substrates, } \\
\text { hydrology, disturbance regimes, and } \\
\text { climate. }\end{array}$ \\
\hline $\begin{array}{l}\text { Regional ecological gradient segment } \\
\text { (often broadly topo-edaphic) } \\
\text { reflected by a set of moderately } \\
\text { diagnostic species (at least a few } \\
\text { species ranges fully contained); } \\
\text { overall composition broadly distinct } \\
\text { from other units. }\end{array}$ & $\begin{array}{l}\text { Regional to subregional gradient segment } \\
\text { (often more narrowly topo-edaphic or } \\
\text { biogeographic), reflected by at least } \\
\text { several moderate diagnostic species, } \\
\text { including from the dominant strata; } \\
\text { overall composition moderately distinct } \\
\text { from other units. }\end{array}$ & $\begin{array}{l}\text { Subregional to local ecological gradient } \\
\text { segment reflected in several } \\
\text { diagnostic species, including } \\
\text { differential species and constant } \\
\text { dominants across strata; overall } \\
\text { composition not well separated from } \\
\text { other units. }\end{array}$ \\
\hline $\begin{array}{l}\text { A set of moderately strong diagnostic } \\
\text { species, preferably with one or more } \\
\text { strong differentials or character } \\
\text { species. Constancy of at least } 25 \% \\
\text { expected for some species. }\end{array}$ & $\begin{array}{l}\text { Several or more moderate diagnostic species, } \\
\text { preferably including at least one strong } \\
\text { differential (character species may be } \\
\text { absent). Constant species more important } \\
\text { for defining type, with at least } 40 \% \\
\text { constancy expected. }\end{array}$ & $\begin{array}{l}\text { At least a few diagnostic species, } \\
\text { preferably including at least one } \\
\text { moderate differential. Constancy } 40- \\
60 \% \text { for a suite of species. }\end{array}$ \\
\hline $\begin{array}{l}\text { Moderately uniform growth forms and } \\
\text { canopy closure, (e.g., varying from } \\
\text { evergreen to deciduous and open to } \\
\text { closed canopy). }\end{array}$ & $\begin{array}{l}\text { Moderately uniform growth forms and } \\
\text { canopy closure, at least in the dominant } \\
\text { layer (e.g., conifer and mixed hardwood, } \\
\text { other layers may vary from shrub to herb } \\
\text { or moss-dominated ground layers with } \\
\text { either open or closed canopy). }\end{array}$ & $\begin{array}{l}\text { Strongly uniform growth forms, in } \\
\text { both dominant and other layers and } \\
\text { degree of canopy closure (e.g., closed } \\
\text { canopy evergreen dominated } \\
\text { shrubland with a primary understory } \\
\text { growth form dominant (sedge forb). }\end{array}$ \\
\hline $\begin{array}{l}\text { Regional mesoclimate. Could indicate } \\
\text { secondary regional gradients } \\
\text { (depends upon selected primary } \\
\text { gradient for macrogroup). }\end{array}$ & $\begin{array}{l}\text { Regional to subregional topo-edaphic } \\
\text { factors, sometimes reflective of } \\
\text { biogeography and climate. }\end{array}$ & $\begin{array}{l}\text { Climate rarely a driver; rather a } \\
\text { narrow range of topo-edaphically } \\
\text { related influences. }\end{array}$ \\
\hline $\begin{array}{l}\text { Moderately consistent disturbance } \\
\text { regime; may incorporate successional } \\
\text { stages that are otherwise floristically } \\
\text { similar. }\end{array}$ & $\begin{array}{l}\text { Moderately specific disturbance regime; may } \\
\text { group successionally related associations. }\end{array}$ & $\begin{array}{l}\text { Narrow range of disturbance regime; } \\
\text { may have disturbance or successional } \\
\text { relationships to other local } \\
\text { associations. }\end{array}$ \\
\hline $\begin{array}{l}\text { Moderate range of variation in specific } \\
\text { topo-edaphic or hydrologic } \\
\text { conditions. }\end{array}$ & $\begin{array}{l}\text { Moderately specific edaphic or hydrologic } \\
\text { conditions, e.g., dry, dry-mesic, mesic, } \\
\text { wet-mesic, or wet moisture conditions and } \\
\text { poor, moderate, moderately rich, or rich } \\
\text { nutrient conditions. }\end{array}$ & $\begin{array}{l}\text { Narrow range of edaphic or hydrologic } \\
\text { conditions, indicative of locally } \\
\text { significant factors, e.g., soil moisture/ } \\
\text { nutrient regimes, soil depth and } \\
\text { texture. Site-scale drivers of } \\
\text { structural variation (e.g., dry } \\
\text { woodlands). }\end{array}$ \\
\hline
\end{tabular}

rain-forest formation. We retain the term formation for the more strictly growth-form-based global type. The division concept also overlaps with the term biome. For example, Rutherford et al. (2006:32) note that, strictly speaking, the term biome includes both plant and animal communities on a continent, but because of the dominant nature of vegetation cover in (nearly) all terrestrial ecosystems, biomes have been based only on vegetation characteristics (see also Ladle and Whittaker [2011]). Thus, the Rutherford et al. Nama Karoo biome (or subcontinental formation) of South Africa is largely equivalent to a division.

With the introduction of the division concept and floristic criteria, the upper-level formation units can be subdivided on the basis of biogeographically distinct regional species pools. Thus the tropical lowland humid forest formation can be divided into Amazonian lowland humid forest, Brazilian-Parana lowland humid forest, Guineo-Congolian evergreen and semievergreen rainforest, and Malagasy evergreen and semievergreen rain forest. Typically, suites of diagnostic (character) species are selected that are restricted to a particular division type, along with the dominant species that express the dominant growth forms. In turn, from the bottom-up, it is the shared growth forms among division types reflecting a set of shared climatic and edaphic factors that leads to their placement within the same formation.

When developing global division units, we consulted Takhtajan (1986), as well as regional biogeographic studies, such as Greller (2000) for North America, Rivas-Martinez et al. (2011) for Latin America, and White (1983) for Africa. These provide useful guides to the scope of biogeographic regions relevant to describing 
division level concepts. These biogeographic classifications are not used to introduce a formal phytogeographic regionalization into the hierarchy (as done by Brown et al. [1998]); rather, they inform us of the likelihood that, for example, Mongolian grasslands share species in common with either European or North American grasslands. Not all formations have patterns relevant to Takhtajan's biogeographic units. For example, whereas the biogeography reflected in the dozen or so divisions for the temperate grassland and shrubland formation correspond closely to Takhtajan's provinces, the two divisions of the mangrove formation do not. Below the division level, large-scale, biogeographic-scale descriptors typically yield to other factors.

By emphasizing the diagnostic value of species or suites of species, the division level facilitates the establishment of lower-level classification units, thus minimizing the need to search for universally valid diagnostic species or genera for those units. The value of diagnostic species groups is clearer among similar habitats within a biogeographic region (Mueller-Dombois and Ellenberg 1974). Species that are widespread and occur across multiple biogeographic regions may have potentially different ecological niches, and thus different diagnostic characteristics among the regions, as discussed by Damman (1979) and Wells (1996) for bog and fen species shared between eastern Canada and Western Europe.

2. Macrogroup (L5).-Macrogroup is defined by "moderate sets of diagnostic plant species and diagnostic growth forms that reflect biogeographic differences in composition and subcontinental to regional differences in mesoclimate, geology, substrates, hydrology, and disturbance regimes" (FGDC 2008; cf. Brown 1982, Pignatti et al. 1994).

The macrogroup is similar to the class level of the Braun-Blanquet approach, which uses the definition of "the common ecological space of the included associations, and recognizable by the occurrence of a common set of characteristic taxa, which are by preference chorologically [biogeographically] homogeneous" (Pignatti et al. 1994:150). According to Pignatti et al. (1994), three primary conditions must be met for the recognition of a Braun-Blanquet class: characteristic taxa, ecology, and biogeography; and one secondary condition, physiognomy. A vegetation class should therefore have a wide geographic distribution. These same conditions appear in the macrogroup definition, but, as with the division, the physiognomic condition plays a more explicit role.

A macrogroup definition should typically contain a moderately large set (dozens) of strongly diagnostic species that share a broadly similar physiognomy and ecology in response to continental, subcontinental, or regional differences in ecological factors (Table 4). Thus, the macrogroup expresses the floristic, growth form, and regional ecological factors that separate vegetation within a division. For example, the Amazonian Lowland
Humid Forest contains a number of macrogroups based on species changes that reflect regional climate and elevational gradients, including Central Amazon Humid Forest, Northern Amazon Humid Forest, Southern Amazon Humid Forest, Southwestern Amazon Lowland Humid Forest, Southwestern Amazon Subandean Humid Forest, Western Amazon Lowland Humid Forest, Western Amazon Subandean Humid Forest. The California Scrub division is based on both a variety of distinct species and distinct growth form patterns, e.g., California Chaparral and the California Coastal Scrub.

When assessing compositional similarity, presence/ absence data (as measured by constancy) may work reasonably well to distinguish the wide diversity of species and growth forms found within and between related macrogroups, though dominance should not be ignored. Analytical tools such as shortest path or stepacross similarity (Boyce and Ellison 2009) can address compositional similarity. Constant species are defined based on a $25 \%$ threshold, given the higher level of heterogeneity among stands at this level, as compared to lower levels (Chytrý and Tichý 2003; and see Pojar et al. [1987], who refer to these as important companion species).

3. Macrogroups and ruderal vegetation.-For the EcoVeg approach, the macrogroup level appears to be a very appropriate level for recognizing ruderal (weedy, invasive, or novel) vegetation, that is, vegetation found on human-disturbed sites (abandoned farmland, quarries, roadsides, or vegetation dominated by invasives; see Basic Categories of the EcoVeg Approach: Natural and cultural vegetation). Ruderal types often contain remnants of the larger regional species pool, as reflected by the division level, but otherwise have a very distinctive species composition. For that reason, macrogroups of ruderal vegetation are labelled as such. For example, within the Eastern North American Cool Temperate Forest division, there are seven native forest macrogroups (e.g., Northern Pine and Oak Hardwood Forest) and one ruderal forest macrogroup (Eastern North American Ruderal Forest). The latter group is typically found on abandoned farm fields that contain both weedy native and invasive exotic forests species (e.g., Acer platanoides Ruderal Forest, Robinia pseudo-acacia Ruderal Forest, and the old field Pinus strobus Ruderal Forest, dominated by Pinus strobus and Acer rubrum, with various invasives shrubs and herbs [e.g., Rhamnus cathartica, Alliaria petiolata]).

The Braun-Blanquet approach also recognizes distinct classes (equivalent to macrogroups) of invasive or weed vegetation, both forested and nonforested (see Rodwell et al. [2002]). The Robinietea of central European vegetation (Chytrý and Tichý 2003) contains anthropogenic tree communities dominated by Robinia pseudoacacia, Acer negundo, and Ailanthus altissima that colonize disturbed habitats, such as deforested lands, cleared forest edges, and agricultural and industrial 
fallows. The Molinio-Arrhenatheretea (anthropogenic pastures and meadows) is an example of a more complicated mix of natural and ruderal vegetation, reflecting the long history of agricultural use on both originally natural and extensively human-created meadows. In Rodwell et al. (2002), this class is treated alongside other native European grassland types. In Hungary, a grid-based vegetation mapping project explicitly distinguished habitats strongly dominated by perennial alien species from habitats containing native species, with or without some proportion of perennial aliens (Botta-Dukát 2008). The former category parallels our ruderal macrogroup.

For a new type to be defined based on invasive plant species, it must contain a new set of diagnostic species in the region and have essentially removed the diagnostic species of existing native types. That is, when invasive species overwhelmingly dominate a stand (e.g., $>90 \%$ cover, but this may vary by type) and native diagnostic species are largely to completely absent, or replaced by new, often "weedy" native species, that stand is placed within a ruderal macrogroup. Setting a high threshold minimizes the creation of new types until it is certain that a new characteristic combination of species has been formed. Such is the case for abandoned exotic tree plantations and post agricultural forests in Europe and the United States; these exhibit some characteristics of more natural vegetation, but differ from a near-natural analog for at least a full generation of trees, during which time native diagnostic species establish (Ellenberg 1988, Flinn and Marks 2007). The same is true of many secondary tropical forests (Zanini et al. 2014).

By expanding the category of natural vegetation to include historic, native, and recent naturalizing and altered vegetation, we provide ecologists with a method that goes beyond a simple dichotomy of pristine nature or not and allows us to document types that reflect the range of influences on natural vegetation. We can then begin to assess the proportion of landscapes that contain native vs. invasive vs. cultural vegetation (Botta-Dukát 2008). There is a long history of interactions between natural and human processes in some regions of the world, and we recognize that it will not always be easy to make these distinctions.

4. Group (L6).-A vegetation unit defined by "a relatively narrow set of diagnostic plant species (including dominants and codominants), broadly similar composition, and diagnostic growth forms that reflect regional mesoclimate, geology, substrates, hydrology, and disturbance regimes" (FGDC 2008; cf. Brown 1982). As with the macrogroup, meeting this definition requires four conditions: characteristic taxa, physiognomy, ecology, and biogeography (see Table 4). It is similar to the order level of the Braun-Blanquet hierarchy (Pignatti et al. 1994).

A group description should contain several to many diagnostic species that share a similar structure and ecology, responding to regional ecological factors, with many moderately differential species or two or more strongly differential (character) species. There should be several diagnostic species in the dominant stratum or growth form, but the diagnostic value is typically that of constancy and dominance. Several dominant growth forms are consistent throughout the type. There may be some variation in dominant overstory species, where overall floristics and ecology are otherwise quite similar (e.g., subalpine larch and Engelmann spruce-subalpine fir with similar site factors and disturbance regimes).

The criterion of compositional similarity addresses the overall range of composition, rather than specific diagnostic species or dominants. Whereas for the macrogroup, presence/absence may play a strong role in discriminating among types (given the large number of species that are expected for macrogroup discrimination), for the group, the abundance of a set of dominant species along with other diagnostic species together play a stronger role in the characteristic species combination. As with macrogroups, a constant species could be as low as $25 \%$ (Chytrý and Tichý 2003).

5. Comparison of middle level units to other classifications.-A number of classifications have parallels to the middle levels of the EcoVeg approach (see also Franklin et al. [2012]). Comparable units have been developed at the class and order level in the Braun-Blanquet classification (Walker et al. 1994, Peinado et al. 1997, 2011, Rivas-Martínez et al. 1999, Spribille 2002, Barbour et al. 2005, Talbot et al. 2005). In British Columbia, a comprehensive set of classes and orders has been described for most vegetation types based on a modification of the Braun-Blanquet approach (Meidinger et al. 2003).

Brown et al. (1998) published an impressively comprehensive list of biotic communities for North America (including Central America). Biotic communities are defined as "regional [biogeographic] plant formations characterized by particular species of plants and animals," that express the multivariate effects of environmental factors and are identified using both dominant and diagnostic species (Brown et al. 1998). The scale of their units is comparable to the macrogroup or group. Although descriptions are only available for the American Southwest, Brown et al. (1998) also produced a list and map for all North American types.

The terrestrial ecological system classification was recently completed by NatureServe for both the United States (Comer et al. 2003) and Latin America (Josse et al. 2003, Sayre et al. 2008). Terrestrial ecological systems are defined as "a group of plant community types that tend to naturally co-occur within similar environmental settings, ecological dynamics, and/or environmental gradients" (Comer and Schulz 2007). Although developed as a single, nonhierarchical set of types, they have a fairly strong correspondence to the EcoVeg group level. Indeed, their concepts were consulted when developing group concepts in North America because, as with groups, system units are derived by a bio-ecosystems 
approach that includes vegetation and ecological factors. Whereas groups rely more strongly on vegetation criteria correlated to ecological factors, systems more directly use ecological factors and landscape pattern together with vegetation to define types. Both systems and EcoVeg groups consist of aggregations of associations (data available online). ${ }^{15}$ Systems guide the mapping legends and successional models of natural ecosystems for the USGS LANDFIRE program (data available online $)^{16}$ and for wildlife habitat characterization of the USGS Gap Analysis Program (Comer and Schulz 2007, Lowry et al. 2007).

Lower levels (L7-L8).-Although not our focus, these levels are briefly defined so that the reader can see how they integrate with L1-L6. For complete descriptions of the lower level units, see FGDC (2008) and Jennings et al. (2009).

1. Alliance.-A classification unit containing one or more associations and defined by a characteristic range of species composition, habitat conditions, physiognomy, and diagnostic species, typically at least one of which is found in the uppermost or dominant stratum of the vegetation. Alliances reflect regional to subregional climate, substrates, hydrology, moisture/nutrient factors, and disturbance regimes. Additional information on the alliance concept is provided in Appendix E, including guidelines, literature review, and glossary of terms.

2. Association.-A classification unit defined on the basis of a characteristic range of species composition, diagnostic species occurrence, habitat conditions, and physiognomy. Associations typically reflect topo-edaphic climate, substrates, hydrology, and disturbance regimes.

The alliance and association concepts have been used widely by various vegetation classification systems (see discussion in Jennings et al. [2009] and Franklin et al. [2012]) but are most fully developed in the BraunBlanquet approach. As outlined in Jennings et al. (2009), the concepts for these two levels has close similarities to that approach (more so than for other levels of the hierarchy) and builds on decades of work applying those terms within North America (Grossman et al. 1998).

3. Subassociations, variants, and phases.-Additional lower levels, such as subassociation, variant, and phases may be developed, if desired. For example, in the USNVC hierarchy, these levels are noted, but not formally included (FGDC 2008). Westhoff and van der Maarel (1973) provide guidance on the definitions and applications of the subassociation and variant levels, and Boublík et al. (2007) provide a contemporary application. The phase level is an optional level that may be used to track levels of alteration caused by human impacts. That is, the phase level can be used to describe the range of variation from minimally disturbed to

\footnotetext{
${ }^{15} \mathrm{http}$ //explorer. natureserve.org/servlet/NatureServe?init= Ecol

${ }^{16} \mathrm{http}: / /$ landfire.cr.usgs.gov/viewer/
}

strongly altered stands, where overall composition, diagnostic species, and invasive species change along that gradient. It then becomes possible to define a limit of alteration, after which the type is so altered that it becomes a ruderal type (see Natural Vegetation: Hierarchy levels for natural vegetation: 3. Macrogroup and ruderal vegetation). Analyses of types may benefit from initially removing altered phases when characterizing floristic and growth form patterns, then adding these phases back in to determine their relationship to minimally disturbed types. The phase level may also be useful at multiple levels of the hierarchy. That is, as the composition of a natural association is altered by human impacts, and invasives and weedy natives increasingly dominate a stand, it may only be possible to assign a stand to an alliance, and as the composition across the alliance is altered, it may only be possible to assign a stand to a group. Very strong alteration could lead to a novel type and placement in a ruderal category.

\section{Type description and review}

Many aspects of type description are discussed in FGDC (2008) and Jennings et al. (2009), including plot data preparation and analysis, interpretation, documentation, and archiving, and type description, nomenclature, and peer review. Those publications focused on the alliances and associations. We focus on the middle and upper levels of the hierarchy.

\section{Vegetation field plots and analyses}

Field plot data collection methods described in FGDC (2008) and Jennings et al. (2009) are suitable for all levels of the hierarchy, since collection methods for physiognomic, floristic, and relevant ecological information are included. A hybrid, nested plot design method for data collection is recommended (Jennings et al. 2009). In particular, we recommend the nested 0.1-ha design with core plot sizes between $100 \mathrm{~m}^{2}$ and $1000 \mathrm{~m}^{2}$ because almost all vegetation can be adequately characterized within these size ranges (Peet et al. 1998, Dengler et al. 2009), though many studies still sample open grass and low shrub vegetation at between $10 \mathrm{~m}^{2}$ and $100 \mathrm{~m}^{2}$ (Dengler et al. 2008, Peet and Roberts 2013). For vegetation that is very species rich and physiognomically complex (e.g., tropical rainforests) or very sparse (e.g., deserts), additional plot sizes of between 0.25 and 1.0 ha may be needed to accurately describe floristics and physiognomy. By using these plot methods, the physiognomy, floristics, and ecology of a wider range of vegetation types can be consistently characterized at multiple spatial scales.

Choosing a nested design, with a relatively narrow range of plot sizes, also increases the compatibility with other plot data and the consistency of the overall data. There is no good ecological reason, apart from differences in stature, to change plot sizes between types with different dominant growth form (e.g., grasslands and forests) in terms of composition, diversity, and 
ecological responses. Studies in Europe have found that vegetation classification analyses are confounded when plots of different sizes are included, because measures of richness and constancy are not comparable (Chytrý 2001, Chytrý and Otýpková 2003, Otýpková and Chytrý 2006, Dengler et al. 2009). Thus careful consideration should be given to the merits of retaining as uniform a plot sampling design as possible within and across vegetation types, anywhere in the world.

The increasing trend toward standardizing vegetation data collection methods and online database repositories is encouraging. In North America, VegBank has helped set standards for plot databases and data collection and can help aggregate the diverse set of plots from across North America (Peet et al. 2012). Additional vegetation databases are documented in the global index of vegetation databases (Dengler et al. 2011). Access to this quantity of global data will allow for large scale analysis of vegetation patterns and clarification of the hierarchy at multiple levels.

\section{Nomenclatural rules}

We continue the approach taken in Jennings et al. (2009), whereby a scientific name, a translated scientific name (based on the vernacular plant names available from widely accepted standard taxonomic references), and a common name are all provided. Translated names and common names are provided in English and other languages. The names can include both physiognomic terms (forest, grassland, bog, tundra) and plant species names, and may also include a biogeographic term. Nomenclatural terms from other classifications can be noted in the field for synonymy.

Upper level nomenclature.-Formation types (L1-L3) are named, defined, and organized by structure and physiognomy to reflect global climatic and site factors. Naming the formations is aided by the use of common terminology (FGDC 2008) reflecting the habitats occupied by a unit (Whitmore 1984:155). A one-sentence descriptive summary is provided for each type. The result is an easily recognizable set of formations with readily memorable names that describe concisely the ecological characteristics of the formation unit. While not developed here, formal Latinized names could be developed for these three levels, as proposed by Rübel (1930-1931, as cited in Shimwell 1971: Appendix II). For example, Deserta for the desert and semidesert class, Siccadeserta for the warm semidesert subclass or Frigorideserta for the cool semidesert subclass.

1. Formation class (L1).-Class names are based on the general growth forms that correspond to global moisture/temperature regimes. The single name identifies the typical growth forms that correspond to particular moisture/temperature conditions, and a parenthetical set of names can be included to inform users as to the main vegetation types included. Given overlapping usage of terms such as forest and woodland, both terms are combined (Forest and Woodland) to indicate that the class definition encompasses all stands dominated by mesomorphic (i.e., broad-leaved or needle-leaved) trees of varying height and canopy spacing. The term grassland is broadly applied to include upland herbaceous (forb and graminoid) dominated vegetation. Formation class names include: Mesomorphic Tree Vegetation (Forest and Woodland), Mesomorphic Shrub and Herb Vegetation (Shrub and Herb Vegetation), Cryomorphic Scrub and Herb Vegetation (Polar and High Montane Scrub and Grassland), Xeromorphic Woodland, Scrub and Herb Vegetation (desert and semidesert), Hydromorphic Vegetation (Aquatic Vegetation), and Rock Vegetation.

2. Formation subclass (L2).-The subclass name reflects the structure, physiognomy, and environmental factors that characterize the unit. The primary environmental factor is macroclimate. Physiognomic terms are sometimes more specific than the formation class name (e.g., scrub vs. shrubland, where the vegetation may include tall, xeromorphic, tree-like plants such as tall cacti or microphyllous-leaved shrubs). All such terms, if used, should be defined. Examples include: Tropical Forest, Temperate and Boreal Grassland and Shrubland, Cool Semidesert Scrub and Grassland, and Saltwater Aquatic Vegetation.

3. Formation (L3).-The formation name reflects the structure, physiognomy, and environmental factors that characterize the formation. The primary environmental factors are soil moisture and elevation. Physiognomic terms are sometimes more specific than the formation class or subclass name. All physiognomic terms should be defined in the vegetation type description. Examples include: Tropical Lowland Humid Forest, Mediterranean Scrub and Grassland, Cool Semidesert Scrub and Grassland, and Marine and Estuarine Saltwater Aquatic Vegetation.

Mid- and lower-level nomenclature.-Lower level nomenclature for alliances and associations is described in Jennings et al. (2009). For mid levels, many of the same guidelines apply. These include:

1) Nomenclature shall contain scientific and colloquial names.

2) Combinations of floristic and physiognomic terms are always used in the name, and biogeographic and ecological terms may be used.

3) Among the taxa that are chosen to name the type (up to three species for mid levels), those occurring in the same stratum or growth form (tree, shrub, herb, nonvascular, floating, submerged) are separated by a hyphen (-) with a space on each side, and those occurring in different strata are separated by a slash (/). Diagnostic taxa occurring in the uppermost stratum are listed first, followed successively by those in lower strata. The order of taxon names within a stratum or growth form generally reflects a dominant of high constancy (whether or not strongly diagnostic), a dominant of moderate to strong diagnostic 
TABLE 5. Example names for macrogroup and group.

See last page for erratum on nomenclature

\begin{tabular}{|c|c|}
\hline Scientific name & Colloquial name \\
\hline \multicolumn{2}{|l|}{ Macrogroup } \\
\hline $\begin{array}{l}\text { Juniperus coahuilensis, Pinus cembroides, Quercus arizonica Woodland } \\
\quad \text { Macrogroup }\end{array}$ & Madrean Lowland Evergreen Woodland \\
\hline $\begin{array}{l}\text { Great Basin and Intermountain Chrysothamnus viscidiflorus, Coleogyne } \\
\text { ramosissima/Achnatherum hymenoides Shrubland and Grassland } \\
\text { Macrogroup }\end{array}$ & $\begin{array}{l}\text { Great Basin and Intermountain Dry Shrubland } \\
\text { and Grassland }\end{array}$ \\
\hline $\begin{array}{l}\text { Acer saccharum, Betula alleghaniensis, Pinus strobus, Tsuga canadensis } \\
\text { Forest Macrogroup }\end{array}$ & Northern Mesic Hardwood and Conifer Forest \\
\hline Acer saccharum, Betula lenta, Quercus rubra Forest Group & $\begin{array}{l}\text { Southern and Central Appalachian Northern } \\
\text { Hardwoods-Hemlock Forest }\end{array}$ \\
\hline \multicolumn{2}{|l|}{ Group } \\
\hline $\begin{array}{l}\text { Acer rubrum, Acer platanoides/Rhamnus cathartica } \text { Ruderal Forest } \\
\text { Macrogroup }\end{array}$ & Eastern North American Ruderal Forest \\
\hline $\begin{array}{l}\text { northern and Central Juniperus virginiana, Liriodendron tulipifera/ } \\
\text { Lonicera tatarica Ruderal Forest Group }\end{array}$ & Northern and Central Old Field Forest \\
\hline
\end{tabular}

value, and a strong diagnostic species, whether or not dominant. Species may meet one or more of these criteria.

4) Physiognomic terms used for middle levels should be as consistent and specific as possible within formations. For example, various mid or lower level units may use physiognomic terms such as grassland, marsh, bog, and woodland. A catalogue of terms and their usage should be maintained to ensure consistency (see Natural Vegetation: Peer review). For example, the term scrub is used to describe vegetation where shrub and tree-like growth forms are hard to distinguish, as in desert and alpine regions, whereas shrubland refers to more typical multistemmed, weakly canopied, mesomorphic-dominated vegetation.

5) Types that fall under the category of natural vegetation but are dominated by invasive species or found on strongly human disturbed habitats, such as old fields on abandoned farm sites or invasive grassdominated rangelands, and which clearly have no analog to historic native vegetation, should be placed in a distinct macrogroup with the term ruderal in the name.

6) Nomenclature for vascular plant taxa should follow the name in an accepted botanical reference (e.g., in the United States, USDA PLANTS database (data available online). ${ }^{17}$ Each plant taxon used in a scientific name shall have only one common name that shall form the basis for the common name of types (e.g., quaking aspen, not aspen or trembling aspen).

At the division level, the names are expected to include biogeographic terms, as large-scale biogeographic patterns play a large role in their concepts. Because it is difficult to choose a few typical species at this scale, scientific and colloquial names may initially be the same. For example, within the Tropical Lowland Grassland,

\footnotetext{
${ }^{17}$ http://plants.usda.gov
}

Savanna and Shrubland, appropriate division names (both scientific and colloquial) include Caribbeo-Mesoamerican Lowland Shrubland, Grassland and Savanna; Brazilian-Parana Lowland Shrubland, Grassland and Savanna; Mopane Savanna; Indo-Malayan Mesic Savanna and Grassland; and Australian Tropical Savanna. See Table 5 for examples of names for macrogroup and group.

Although our nomenclatural approach allows for somewhat lengthy scientific names, it is concerned with clarity, and provides a concise common name accessible to many users, as is typical of biological nomenclature for at least larger sized organisms, such as plants, insects, birds, and fish.

\section{Description template}

The template provided in Jennings et al. (2009: Box 2) is appropriate for describing units at all levels of the hierarchy (see also FGDC [2008: Section 3.2.3]). The specifications for describing a type including: (1) a standard template is used, supplemented with a few additional fields for data management purposes. (2) A standard set of growth forms is used, as provided in Appendix C. These should be consulted to maintain consistent concepts. Growth form types are placed in italics to remind the reader that the terms have specific meanings. Additional growth forms will be added as needed. Over time, biogeographic terms and scientific sources for species names will be added. (3) The descriptions can be submitted to a coordinating body established for a country or regions.

\section{Peer review}

The approach to peer review described by Jennings et al. (2009) is applicable for those adopting the EcoVeg approach. The process is based on a dynamic classification standard, where peer review is an open process conducted by professional organizations in collaboration with other interested parties. It is administered by a peer review board under the aegis of an institution or institutions capable of providing independent reviewers 
with experience in vegetation classification. Currently, NatureServe manages the data content for the International Vegetation Classification, working in collaboration with international partners, such as International Union for Conservation of Nature, World Wildlife Fund, The Nature Conservancy, International Association of Vegetation Science, a variety of agencies, organizations and academic scientists, and with national projects, such as the USNVC and Canadian National Vegetation Classification (CNVC). Whether a more formal international body can be developed will depend on the interests of vegetation ecologists around the world (see also Implementing the EcoVeg Approach).

\section{Cultural Vegetation}

\section{Criteria for the description of cultural vegetation}

Vegetation criteria are the primary properties used to define all units of cultural vegetation, but the role of human management processes is often much stronger than ecological or biogeographic processes. Excluded from the vegetation criteria are explicit habitat factors (e.g., climate, soil type) or land use practices (e.g., grazed pasture vs. ungrazed pasture), except as these are expressed in the vegetation. Some types are difficult to place in terms of natural vs. cultural vegetation (e.g., some intensively managed forests, some pastures), and the user may need to look in both parts of the hierarchy to determine the type's location.

The criteria for classifying cultural vegetation include growth forms, floristics, and ecological setting (Di Gregorio and Jansen 1996). The definition of terms used for cultural vegetation criteria largely correspond to that of natural vegetation (see Natural Vegetation: Criteria for the description of natural vegetation), but compositional similarity is not a primary criterion, given the monodominance of many cultural vegetation types. Some common characteristics of cultural vegetation include (1) regularly spaced vegetation with substantial cover of bare soil for significant periods of the year (e.g., tillage, chemical treatment, or agricultural flooding), (2) dominant growth forms or structure are highly manipulated and rarely found in natural vegetation (e.g., mechanical pruning, mowing, clipping, etc.), and (3) dominant vegetation comprised of planted, nonnative species.

Growth forms.-As with the natural vegetation, growth form criteria include (1) diagnostic patterns of growth forms, (2) dominant growth forms, singly or in combination, and (3) vertical and horizontal structure of growth forms (Di Gregorio and Jansen 1996). Distinctive sets of cultural growth forms are not currently described, but will be needed (orchard tree, vineyard grape, row crop, etc.).

Floristics.-Floristic (crop or managed species) criteria include (1) diagnostic combinations of species/crop or managed types, (2) dominant species, reflecting similar agricultural or developed vegetation patterns, and (3) vertical and horizontal structure of species.
Together these criteria are evaluated in a human management context.

Ecological context.-Criteria for ecological context include (1) climate (macro, meso, and microclimate), though human management activities often overcompensate for many of the climatic effects, except at the extremes (frost free climates, extreme cold or drought climates), (2) effects of human activities (e.g., plowing, mowing), and (3) topo-edaphic factors, including creation of ponds, plowing, modifications of $\mathrm{pH}$, moisture, nutrients, and texture. Because many crop species are planted and maintained outside their provenance, biogeography is rarely considered in the description of cultural types.

All type concepts based on these criteria should be derived from field observations, in which the crops or managed species, growth forms, and their abundances, along with the field observation record, overall vegetation structure, management activities, and habitat setting are described. These field data provide the fundamental information for the description of types. All types at all levels should be described and characterized.

\section{Hierarchy levels for cultural vegetation}

As with natural vegetation, the hierarchy consists of eight levels that are aggregated into three sets, but physiognomy plays a greater role for classifying cultural vegetation. The criteria outlined in Cultural Vegetation: Criteria for the description of cultural vegetation are used to develop descriptions of each unit in the hierarchy, with the utility and relevance of the criteria varying by level. In this section, we provide the names, definition, and descriptions for each of the levels (see also Table 6), following FGDC (2008).

Cultural upper levels (L1-L4).-As with natural vegetation, physiognomic criteria are the primary properties of cultural vegetation used to define the four upper levels. The formation concept, as discussed for natural vegetation, is relevant to cultural vegetation too, but units are assessed in light of human activities that govern their properties.

1. Cultural class (L1).-Cultural class is defined by a broad and characteristic combination of dominant growth forms adapted to relatively intensive human management, as reflected in relatively rapid changes in structure and/or composition. Relatively intensive human management refers to activities affecting vegetation composition and/or structure that occur from multiple times in a year (haying, mowing) to decadal (thinning of forest structure, orchard pruning, swidden slash and burn cycles).

2. Cultural subclass (L2).-Cultural subclass is defined by a broad combination and degree of herbaceous vs. woody growth forms that reflect widespread human management activities. The types are based on broadly distinct growth form combinations, including herbaceous vs. woody vs. aquatic cultural vegetation types. 
TABLE 6. Levels, definitions, and examples of the hierarchy for cultural vegetation (see FGDC 2008).

\begin{tabular}{|c|c|c|c|c|c|}
\hline \multirow[b]{2}{*}{ Cultural hierarchy } & \multirow[b]{2}{*}{ Definition (FGDC 2008) } & \multicolumn{2}{|c|}{ Example 1 names } & \multicolumn{2}{|c|}{ Example 2 names } \\
\hline & & Scientific & Colloquial & Scientific & Colloquial \\
\hline \multicolumn{6}{|l|}{ Upper levels } \\
\hline L1: Cultural class & $\begin{array}{l}\text { defined by a broad and } \\
\text { characteristic } \\
\text { combination of } \\
\text { dominant growth } \\
\text { forms adapted to } \\
\text { relatively intensive } \\
\text { human manipulations, } \\
\text { as reflected in relatively } \\
\text { rapid changes in } \\
\text { structure and/or } \\
\text { composition }\end{array}$ & $\begin{array}{l}\text { Anthromorphic } \\
\text { Vegetation }\end{array}$ & $\begin{array}{l}\text { Agricultural and } \\
\text { Developed } \\
\text { Vegetation }\end{array}$ & $\begin{array}{l}\text { Anthromorphic } \\
\text { Vegetation }\end{array}$ & $\begin{array}{l}\text { Agricultural and } \\
\text { Developed } \\
\text { Vegetation }\end{array}$ \\
\hline L2: Cultural subclass & $\begin{array}{l}\text { defined by broad } \\
\text { combinations and } \\
\text { degree of herbaceous } \\
\text { versus woody growth } \\
\text { forms that reflects } \\
\text { global human } \\
\text { management activities }\end{array}$ & $\begin{array}{l}\text { Herbaceous } \\
\text { Agricultural } \\
\text { Vegetation }\end{array}$ & $\begin{array}{l}\text { Herbaceous } \\
\text { Agricultural } \\
\text { Vegetation }\end{array}$ & $\begin{array}{l}\text { Woody } \\
\text { Agricultural } \\
\text { Vegetation }\end{array}$ & $\begin{array}{l}\text { Woody } \\
\text { Agricultural } \\
\text { Vegetation }\end{array}$ \\
\hline L3: Cultural formation & $\begin{array}{l}\text { defined by the degree to } \\
\text { which canopy structure } \\
\text { of dominant growth } \\
\text { forms is annually } \\
\text { converted or heavily } \\
\text { manipulated/harvested }\end{array}$ & $\begin{array}{l}\text { Row and Close } \\
\text { Grain Crop }\end{array}$ & $\begin{array}{l}\text { Row and Close } \\
\text { Grain Crop }\end{array}$ & $\begin{array}{l}\text { Forest } \\
\text { Plantation } \\
\text { and } \\
\text { Agroforestry }\end{array}$ & $\begin{array}{l}\text { Forest } \\
\text { Plantation and } \\
\text { Agroforestry }\end{array}$ \\
\hline L4: Cultural subformation & $\begin{array}{l}\text { defined by the spatial } \\
\text { structure of the } \\
\text { Vegetation, including } \\
\text { whether in swards, } \\
\text { rows, and degree of } \\
\text { manipulation to the } \\
\text { canopy }\end{array}$ & $\begin{array}{l}\text { Graminoid } \\
\text { Row Crop }\end{array}$ & $\begin{array}{l}\text { Graminoid Row } \\
\text { Crop }\end{array}$ & $\begin{array}{l}\text { Forest } \\
\quad \text { Plantation }\end{array}$ & $\begin{array}{l}\text { Forest } \\
\quad \text { Plantation }\end{array}$ \\
\hline \multicolumn{6}{|l|}{ Mid levels } \\
\hline L5: Cultural group & $\begin{array}{l}\text { defined by a common set } \\
\text { of growth forms and } \\
\text { many diagnostic plant } \\
\text { taxa sharing a broadly } \\
\text { similar region and } \\
\text { climate, and } \\
\text { disturbance factors }\end{array}$ & $\begin{array}{c}\text { Tropical and } \\
\text { Temperate } \\
\text { Corn Crop }\end{array}$ & $\begin{array}{c}\text { Tropical and } \\
\text { Temperate } \\
\text { Corn Crop }\end{array}$ & $\begin{array}{l}\text { Temperate and } \\
\text { Boreal } \\
\text { Conifer and } \\
\text { Hardwood } \\
\text { Plantation }\end{array}$ & $\begin{array}{l}\text { Temperate and } \\
\text { Boreal Conifer } \\
\text { and } \\
\text { Hardwood } \\
\text { Plantation }\end{array}$ \\
\hline L6: Cultural subgroup & $\begin{array}{l}\text { defined by a common set } \\
\text { of growth forms and } \\
\text { diagnostic species } \\
\text { (taxa) preferentially } \\
\text { sharing a similar set of } \\
\text { regional edaphic, } \\
\text { topographic, and } \\
\text { disturbance factors }\end{array}$ & $\begin{array}{l}\text { Temperate } \\
\text { Corn Crop }\end{array}$ & $\begin{array}{l}\text { Temperate Corn } \\
\text { Crop }\end{array}$ & $\begin{array}{l}\text { Native Eastern } \\
\text { North } \\
\text { American } \\
\text { Conifer and } \\
\text { Hardwood } \\
\text { Plantation }\end{array}$ & $\begin{array}{l}\text { Native Eastern } \\
\text { North } \\
\text { American } \\
\text { Conifer and } \\
\text { Hardwood } \\
\text { Plantation }\end{array}$ \\
\hline \multicolumn{6}{|l|}{ Lower levels } \\
\hline L7: Cultural type & $\begin{array}{l}\text { defined by one or more } \\
\text { dominant or } \\
\text { codominant species, as } \\
\text { well as habitat } \\
\text { conditions and } \\
\text { physiognomy }\end{array}$ & Zea mays Crop & $\begin{array}{l}\text { Maize Corn } \\
\text { Crop }\end{array}$ & $\begin{array}{l}\text { Pinus strobus- } \\
\quad \text { Pinus } \\
\text { resinosa- } \\
\text { Pinus } \\
\text { banksiana } \\
\text { Native } \\
\text { Plantation }\end{array}$ & $\begin{array}{l}\text { Native White- } \\
\text { Red-Jack Pine } \\
\text { Plantation }\end{array}$ \\
\hline L8: Cultural subtype & $\begin{array}{l}\text { defined by one or more } \\
\text { dominant or } \\
\text { codominant species, in } \\
\text { conjunction with a } \\
\text { characteristic set of } \\
\text { associated species, } \\
\text { habitat conditions, and } \\
\text { physiognomy }\end{array}$ & $\begin{array}{l}\text { Zea mays var. } \\
\text { saccharata- } \\
\text { Zea mays } \\
\text { var. rugosa } \\
\text { Crop }\end{array}$ & $\begin{array}{l}\text { Sweet Corn } \\
\text { Crop }\end{array}$ & $\begin{array}{l}\text { Pinus strobus } \\
\text { Plantation }\end{array}$ & $\begin{array}{l}\text { White Pine } \\
\text { Plantation }\end{array}$ \\
\hline
\end{tabular}

Notes: The name of the level can be added to the type name for clarity, where needed. Scientific names are not well developed for all levels of the cultural hierarchy. 
3. Cultural formation (L3).-Cultural formation is defined by the degree to which canopy structure of dominant growth forms is annually converted or heavily manipulated/harvested.

4. Cultural subformation (L4).-Cultural subformation is defined by the spatial structure and specific growth form dominance of the vegetation, including whether in swards, rows, and degree of manipulation to the canopy.

The comprehensive set of cultural formation types for the top three levels is provided in Appendix C.

Cultural mid-levels (L5-L6).-For the mid-level units, the combination of criteria based on the specific dominant growth forms, genera, and species that comprise cultural vegetation are applied.

1. Cultural group (L5).-Cultural group is defined by a common set of growth forms and many diagnostic plant taxa sharing a broadly similar region and climate, and disturbance factors.

2. Cultural subgroup (L6).-Cultural subgroup is defined by a common set of growth forms and diagnostic species (taxa) preferentially sharing a similar set of regional edaphic, topographic, and disturbance factors.

Cultural lower levels (L7-L8).-For the cultural type level, emphasis is given to the assemblage of dominant or codominant species, along with the associated species, habitat conditions, and physiognomy. At the subtype level, species compositional variation can be recognized within a dominant crop type, reflecting different soils or different treatments.

1. Cultural type (L7).-Cultural type is defined by one or more dominant or codominant species, as well as habitat conditions and physiognomy.

2. Cultural subtype (L8).-Cultural subtype is defined on the basis one or more dominant or codominant species, in conjunction with a characteristic set of associated species, habitat conditions, and physiognomy.

Examples of cultural types for all levels are provided in Table 6 .

The development of a global cultural vegetation hierarchy is relatively novel and has no parallels in other global vegetation classifications. By the same token, it needs further testing and review, including in the name of the levels. For the United States, a comprehensive set of cultural vegetation types is available in pilot form for most levels, based on the Natural Resources Conservation Service's National Resources Inventory (NRI; see FGDC [2008: Appendix I]). These may prove valuable as a global set of cultural types, pending further review.

\section{Type description, peer review, and analyses}

Guidelines for the classification of cultural vegetation needs further development and will be developed in the future with interested parties. In the meantime, standards for natural vegetation may be followed, as desired (see Natural Vegetation: Type description and review;
Natural Vegetation: Peer review; and Natural Vegetation: Vegetation field plots and analyses).

\section{Nomenclatural rules}

As with natural vegetation, the EcoVeg approach includes a scientific name, a translated scientific name (from the vernacular plant names available from widely accepted standard taxonomic references), and a common name (Table 6). Translated names and common names are provided in English and in a variety of other common languages. The names can include both physiognomic terms (forest, grassland, bog, tundra) and species names and may also include a human management term. Nomenclatural terms from other classifications can also be noted in synonymy fields. The guidelines for naming cultural vegetation needs further development and will be developed in the future with interested parties. Examples are provided in Table 6.

\section{Implementing the Ecoveg ApproACH}

Development of the EcoVeg approach has spanned 12 years, during which time we have had the opportunity to work with state, regional, and national partners to test and refine the approach. At the national level, the USNVC partnership catalyzed our initial efforts (FGDC 2008, Peet 2008, Faber-Langendoen et al. 2009, Jennings et al. 2009, Franklin et al. 2012), assisted by partnerships with the CNVC (Alvo and Ponomarenko 2003, Baldwin and Meades 2008), and the Bolivian vegetation classification (Navarro 2011). Partnerships in the United States and Canada have also been strong at the provincial and state level, allowing for rigorous applications of finescaled concepts (e.g., Hoagland [2000] and Sawyer et al. [2009], among many, as documented in Grossman et al. [1998] and Alvo and Ponomarenko [2003]). Development of the EcoVeg approach across the western hemisphere has been greatly assisted by the prior development of the NatureServe terrestrial ecological systems classification (Comer et al. 2003, Josse et al. 2003), which provided midscale units comparable to group units. Subsequently, various multijurisdictional collaborations emerged, including in the Andes (Josse et al. 2009) and Africa (Sayre et al. 2013). Collaboration with IUCN and WWF on a global grasslands classification has helped refine our approach (Faber-Langendoen and Josse 2010, Dixon et al. 2014). Discussions with European colleagues have produced a better understanding of the relationship between this approach and both the Braun-Blanquet approach (Rodwell et al. 2002) and the European Nature Information System (EUNIS; Davies et al. 2004).

Thus, our system is now well-developed for application across large parts of the globe. NatureServe maintains all International Vegetation Classification units in an institutional database, posts North American units online, and is working to make all units across the globe available publicly. ${ }^{18}$ The comprehensive and multiscale

\footnotetext{
${ }^{18}$ natureserve.org/explorer
} 
set of types documented by the EcoVeg approach will aid in documenting at-risk status of ecosystems under IUCN's emerging red list of ecosystems (see Rodríguez et al. [2011] and Keith et al. [2013]). IUCN and partner ecologists require ecological classifications, including terrestrial, freshwater, marine, and subterranean, to guide red listing efforts, both nationally and internationally. Although these classifications may take a variety of forms at national or subnational levels, their contribution to a global ecosystem red list would be greatly facilitated by the multilevel hierarchy such as that provided here and through the IVC. The IVC could serve as a reporting framework for integrating national information relevant to various levels of terrestrial ecosystem types, in much the same way that the WWF ecoregions have provided one source of standardized units for reporting ecoregional conservation status (Olson et al. 2001). The IVC is already strongly compatible at the formation level with the terrestrial component of IUCN's species habitat classification scheme (version 3.0 2007; available online). ${ }^{19}$ Improving the IUCN habitats to IVC compatibility could greatly facilitate reporting of both the ecosystem red lists and the description of the species-habitat relations for species red lists.

In conclusion, the EcoVeg approach is now able to address many core needs for vegetation description and classification, and sets the stage for further research. It can describe existing vegetation patterns, including both cultural (planted and dominated by human processes) and natural (spontaneously formed and dominated by ecological processes). By providing a set of hierarchical units for both cultural and natural vegetation (including ruderal or novel vegetation), the EcoVeg approach is able to describe the full range of anthropogenic and ecological influences on vegetation patterns. The approach to description and classification of cultural vegetation types requires more research.

EcoVeg describes vegetation types at multiple thematic-scales, from thematically coarse formations (biomes) to fine-scale associations (biotopes). The eightlevel hierarchy for both cultural and natural vegetation draws on well-established traditions of classification in vegetation ecology, compiling both the existing information on vegetation types and providing a peer-review based process for improving and documenting new types.

EcoVeg can inventory vegetation and ecosystem patterns within and across landscape/ecoregional units. In combination with the terrestrial ecological systems classification, the EcoVeg approach provides maps of units at the group or macrogroup level and above for the United States, South America, and Africa. The geographic distribution of all major grassland divisions around the globe is now available (Dixon et al. 2014).

\footnotetext{
${ }^{19}$ www.iucnredlist.org/technical-documents/classificationschemes/habitats-classification-scheme-ver3
}

It can support the documentation of status and trends of vegetation and ecosystems (e.g., trends in extends, trends in condition). The current conservation status of macrogroups and systems in the western hemisphere is being assessed as part of the IUCN red list of ecosystems project (Keith et al. 2013; Comer et al., unpublished manuscript) and complements the global and state/ provincial assessments of at-risk associations in the United States and Canada (Grossman et al. 1998).

EcoVeg facilitates the interpretation of long-term change in vegetation with short-term change of existing vegetation, based on multiple vegetation criteria (growth forms, structure, floristics, etc.). Short-term changes can now be examined at multiple thematic scales to assess types from association to formation scales. Long-term changes can be examined using mid-level types documented in the paleoecological record. Delcourt and Delcourt (1987) used multiple thematic scales, including a level corresponding to the division, to show how vegetation and environmental change varies from dynamic equilibrium to disequilibrium over the last 60000 years, in contrast to a simple transitory view of vegetation at one level, the community, and a stable physical template on the other (Hunter et al. 1988). Similarly, the late quaternary biomes documented by Williams et al. (2000) in the eastern United States have parallels to current existing biomes at the division and macrogroup level of the EcoVeg approach. The slower rates of historical change for these units, i.e., their persistence over longer periods of time, as compared to the lower level units of alliance and association, opens up new avenues of discussion on vegetation change and conservation applications (Delcourt 2002).

The EcoVeg approach can provide a structure to track real-time ecosystem responses to invasive species, land use, and climate change. The EcoVeg approach treats invasives both at the level of variants within natural types, for example, where they can be an indication of degradation of types characterized by native species, and ultimately, should native species disappear from stands, as a basis for describing new types. For all these reasons, we encourage the use of the EcoVeg approach to describe and classify vegetation.

\section{ACKNOWLEDGMENTS}

Our international team contributed to and strongly benefitted from the revised U.S. National Vegetation Classification (USNVC) standard (FGDC 2008), which is supported by a partnership between U.S. federal agencies, the Ecological Society of America Vegetation Classification Panel, and NatureServe, working through the Federal Geographic Data Committee (FGDC) Vegetation Subcommittee. They agreed to sponsor the Hierarchy Revisions Working Group (HRWG), with both national and international expertise. In particular, we thank Ralph Crawford, chair of the FGDC vegetation subcommittee for his many years of support and Alexa McKerrow for her coordination of the many activities required to implement the revised USNVC standard. We gratefully acknowledge the support of the U.S. federal agencies that helped fund the work of the Hierarchy Revisions Working Group from 2003 to 2012, particularly the U.S. Forest Service, 
the interagency LANDFIRE team, U.S. Geological Survey, and National Park Service, as well as the Bureau of Land Management, the U.S. Fish and Wildlife Service, and the Environmental Protection Agency. We thank Sherm Karl, Otto Huber, and Andy Gray, former members of the HRWG, for their input at critical stages early on in the development of the formations. We thank colleagues from the Canadian National Vegetation Classification Technical Committee, led by Ken Baldwin, for their ongoing feedback at various stages of development of this approach.

We appreciate the support and review from members of the Ecological Society of America Vegetation Classification Panel. In particular, we thank Scott Franklin for his comments and for facilitating review among the panel and international ecologists and Janet Franklin, Mike Jennings, Chris Lea, Orie Loucks, Este Muldavin, Bob Peet, Dave Roberts, and John Sawyer for their peer review of this and related documents.

We thank Ken Baldwin, John Benson, Elgene Box, Milan Chytrý, Jürgen Dengler, David Keith, Jesus Izco, and Michael Rutherford for their reviews. Milan Chytrý, Jürgen Dengler, John Rodwell, and Joop Schaminée also provided European perspectives on the development of alliance units and on the Braun-Blanquet approach in general. We thank Andrew Gillison for his extensive comments provided as journal reviewer and insights on plant functional types.

Throughout, NatureServe senior ecology staff have been a solid rock on which to stand, as we considered various approaches. We especially thank Shannon Menard, Milo Pyne, Marion Reid, and Lesley Sneddon for their many contributions. We thank Mary Russo and Kristin Snow for maintaining and editing both the USNVC and the IVC databases. Their data management skills have been invaluable in maintaining the quality of our information.

\section{Literature Cited}

Adam, P. 1992. Australian rainforests. Oxford University Press, London, UK.

Aleksandrova, V. D. 1973. Russian approaches to classification. Pages 493-527 in R. H. Whittaker, editor. Handbook of vegetation science. Part V. Ordination and classification of communities. W. Junk, The Hague, The Netherlands.

Alvo, R., and S. Ponomarenko. 2003. Vegetation classification standard for Canada workshop: 31 May-June 22000. Canadian Field Naturalist 117(1):125-139.

Austin, M. P. 1985. Continuum concept, ordination methods and niche theory. Annual Review of Ecology and Systematics 16:39-61.

Austin, M. P. 2013. Vegetation and environment: discontinuities and continuities. Pages 71-106 in E. van der Maarel and J. Franklin, editors. Vegetation ecology. Second edition. Wiley-Blackwell, New York, New York, USA.

Bailey, R. G. 1989a. Ecoregions of the continents (map). U.S. Forest Service, Washington, D.C., USA.

Bailey, R. G. 1989b. Explanatory supplement to the ecoregions map of the continents. Environmental Conservation 15:307309.

Bailey, R. G. 1996. Ecosystem geography: from regions to sites. Second edition. Springer, New York, New York, USA.

Baldwin, K. A., and W. J. Meades. 2008. Canadian National Vegetation Classification. Pages 66-69 in S. S. Talbot, editor. Proceedings of the Fourth International Conservation of Arctic Flora and Fauna (CAFF) Flora Group Workshop, Torshavn, Faroe Islands, 15-18 May 2007. CAFF Technical Report No.15. Conservation of Arctic Flora and Fauna, Akureyri, Iceland.

Barbour, M. G., and W. D. Billings. 2000. North American terrestrial vegetation. Second edition. Cambridge University Press, New York, New York, USA.

Barbour, M. G., A. I. Solomeshch, R. F. Holland, C. W. Witham, W. Carol, R. L. Macdonald, S. S. Cilliers, J. A. Molina, J. Buck, and J. M. Hillman. 2005. Vernal pool vegetation of California: communities of long-inundated deep habitats. Phytocoenologia 35:177-200.

Beard, J. S. 1973. The physiognomic approach. Pages 355-386 in R. H. Whittaker, editor. Handbook of vegetation science. Part V. Ordination and classification of communities. Springer, The Hague, The Netherlands.

Beckage, B., B. Osborne, D. G. Gavin, C. Pucko, T. Siccama, and T. Perkins. 2008. A rapid upward shift of a forest ecotone during 40 years of warming in the Green Mountains of Vermont. Proceedings of the National Academy of Sciences USA 105:4197-4202.

Beckingham, J. D., I. G. W. Corns, and J. H. Archibald. 1996. Field guide to ecosites of west-central Alberta. University of British Columbia Press, Vancouver, British Columbia, Canada.

Belnap, J., J. A. Ludwig, B. P. Wilcox, J. L. Betancourt, W. R. J. Dean, B. D. Hoffman, and S. J. Milton. 2012. Introduced and invasive species in novel rangeland ecosystems: friends or foes? Rangeland Ecology and Management 65:569-578.

Bestelmeyer, B. T., J. E. Herrick, J. R. Brown, D. A. Trujillo, and K. M. Havstad. 2004. Land management in the American Southwest: a state-and-transition approach to ecosystem complexity. Environmental Management 34:3851.

Bohn, U., R. Neuhäusl, G. Gollub, C. Hettwer, Z. Neuhäuslová, Th. Raus, H. Schlüter, and H. Weber. 2000-2003. Map of the natural vegetation of Europe. Scale 1:2500000. Landwirtschaftsverlag, Münster, Germany.

Bontemps, S., P. Defourny, E. Van Bogaert, O. Arino, V. Kaliogirou, and J. Ramos Perez. 2009. GlobCover 2009: product description and validation report. Université Catholique de Louvain and European Space Agency, Louvainla-Neuve, Belgium.

Borhidi, A. 1991. Phytogeography and vegetation ecology of Cuba. Akadémiai Kiadó, Budapest, Hungary.

Botta-Dukát, Z. 2008. Invasion of alien species to Hungarian (semi-)natural habitats. Acta Botanica Hungarica 50(Supplement):219-227.

Boublík, K., P. Petř́k, J. Sádlo, R. Hédl, W. Willner, T. Černý, and J. Kolbek. 2007. Calcicolous beech forests and related vegetation in the Czech Republic: a comparison of formalized classifications. Preslia 79:141-161.

Box, E. O. 1981. Macroclimate and plant forms: an introduction to predictive modeling in phytogeography. Springer, The Hague, The Netherlands.

Box, E. O. 2002. Vegetation analogs and differences in the northern and southern hemispheres: a global comparison. Plant Ecology 163:139-154.

Box, E. O., and K. Fujiwara. 2005. Vegetation types and their broad-scale distribution. Pages 106-128 in E. van der Maarel, editor. Vegetation ecology. Blackwell Publishing, Malden, Massachusetts, USA.

Boyce, R. L., and P. Ellison. 2009. Choosing the best similarity index when performing fuzzy set ordination on binary data. Journal of Vegetation Science 12:711-720.

Brown, D. 1982. The biotic communities of the American Southwest, United States and Mexico. Desert plants 4. University of Utah Press, Salt Lake City, Utah, USA.

Brown, D. E., C. H. Lowe, and C. P. Pase. 1979. A digital classification system for the biotic communities of North America, with community (series) and association examples for the Southwest. Journal of the Arizona-Nevada Academy of Science 14(Supplement 1):1-16.

Brown, D. E., F. Reichenbacher, and S. E. Franson. 1998. A classification of North American biotic communities. University of Utah Press, Salt Lake City, Utah, USA.

Bruelheide, H. 2000. A new measure of fidelity and its application to defining species groups. Journal of Vegetation Science 11:167-178. 
Bryant, R. B., and J. M. Galbraith. 2003. Incorporating anthropogenic processes in soil classification. Pages 57-66 in H. Eswaran, T. Rice, R. Ahens, and B. A. Stewart, editors. Soil classification: a global desk reference. CRC Press, New York, New York, USA.

Chiarucci, A., M. Araújo, G. Decocq, C. Beierkuhnlein, and J. M. Fernández-Palacios. 2010. The concept of potential natural vegetation: an epitaph? Journal of Vegetation Science 21:1172-1178.

Chytrý, M. 2001. Phytosociological data give biased estimates of species richness. Journal of Vegetation Science 12:439444.

Chytrý, M. 2007. Vegetace České republiky 1. Travinná a keříćková vegetace. [Vegetation of the Czech Republic 1. Grassland and heathland vegetation.] Academia, Prague, Czech Republic.

Chytrý, M. 2012. Vegetation of the Czech Republic: diversity, ecology, history and dynamics. Preslia 84:427-504.

Chytrý, M., and Z. Otýpková. 2003. Plot sizes used for phytosociological sampling of European vegetation. Journal of Vegetation Science 14:563-570.

Chytrý, M., J. H. J. Schaminée, and A. Schwabe. 2011. Vegetation survey: a new focus for applied vegetation science. Applied Vegetation Science 14:435-439.

Chytrý, M., and L. Tichý. 2003. Diagnostic, constant and dominant species of vegetation classes and alliances of the Czech Republic: a statistical revision. Masarykianae Brun 108:1-231.

Chytrý, M., L. Tichý, J. Holt, and Z. Botta-Dukát. 2002. Determination of diagnostic species with statistical fidelity measures. Journal of Vegetation Science 13:79-90.

Comer, P., et al. 2003. Ecological systems of the United States: a working classification of U.S. terrestrial systems. NatureServe, Arlington, Virginia, USA.

Comer, P., and K. Schulz. 2007. Standardized ecological classification for meso-scale mapping in southwest United States. Rangeland Ecology and Management 60:324-335.

Cowardin, L. M., V. Carter, F. C. Golet, and E. T. LaRoe. 1979. Classification of the wetlands and deepwater habitats of the United States. U.S. Fish and Wildlife Service, Washington, D.C., USA.

Cramer, W. 1997. Using plant functional types in a global vegetation model. Pages 271-288 in T. M. Smith, H. H. Shugart, and F. I. Woodward, editors. Plant functional types: their relevance to ecosystem properties and global change. Cambridge University Press, New York, New York, USA.

Curtis, J. T. 1959. The vegetation of Wisconsin: an ordination of plant communities. University of Wisconsin Press, Madison, Wisconsin, USA.

Damman, A. W. H. 1979. Amphi-Atlantic correlations in the Oxycocco-Sphagnetea: a critical evaluation. Documents Phytosociologiques N.S. 4:187-195.

Daubenmire, R. F. 1968. Plant communities: a textbook of plant synecology. Harper and Row, New York, New York, USA.

Davies, C. E., D. Moss, and M. O. Hill. 2004. EUNIS habitat classification revised 2004. Report to the European Topic Centre on Nature Protection and Biodiversity. European Environment Agency, Copenhagen, Denmark.

De Cáceres, M., and S. Wiser. 2012. Towards consistency in vegetation classification. Journal of Vegetation Science 23:387-393.

Delcourt, H. R. 2002. Forests in peril: tracking deciduous trees from ice-age refuges into the greenhouse world. MacDonald and Woodward Publishing, Blacksburg, Virginia, USA.

Delcourt, P. A., and H. R. Delcourt. 1987. Long-term forest dynamics of the temperate zone: a case sudy of lateQuaternary forests in eastern North America. Ecological Studies 63. Springer-Verlag, New York, New York, USA.

Dengler, J., M. Chytrý, and J. Ewald. 2008. Phytosociology. Pages 2767-2779 in S. E. Jørgensen, and B. D. Fath, editors.
Encyclopedia of Ecology. Elsevier Science, Philadelphia, Pennsylvania, USA.

Dengler, J., et al. 2011. The global index of vegetation-plot databases (GIVD): a new resource for vegetation science. Journal of Vegetation Science 22:582-597.

Dengler, J., S. Löbel, and C. Dolnik. 2009. Species constancy depends on plot size-a problem for vegetation classification and how it can be solved. Journal of Vegetation Science 20:754-766.

Devillers, P., and J. Devillers-Terschuren. 1996. A classification of Palaearctic habitats. Nature and environment, No 78. Council of Europe Publishing, Strasbourg, France.

Devillers, P., J. Devillers-Terschuren, and J.-P. Ledant. 1991. CORINE biotopes manual. Volume 2. Habitats of the European community. Office for Official Publications of the European Communities, Luxembourg.

Di Gregorio, A., and L. J. M. Jansen. 1996. FAO land cover classification: a dichotomous, modular-hierarchical approach. Food and Agriculture Organization of the United Nations, Rome, Italy.

Dierschke. H. 1997. Syntaxonomical survey of European beech forests: some general conclusions. Annali di Botanica 55:1726.

Dixon, A., D. Faber-Langendoen, C. Josse, J. Morrison, and C. J. Loucks. 2014. Distribution mapping of world grassland types. Journal of Biogeography. http://dx.doi.org/10.1111/ jbi.12381

Driscoll, R. S., D. L. Merkel, D. L. Radloff, D. E. Snyder, and J. S. Hagihara. 1984. An ecological land classification framework for the United States. U.S. Forest Service Miscellaneous Publication 1439. U.S. Forest Service, Washington, D.C., USA.

Dufrêne, M., and P. Legendre. 1997. Species assemblages and indicator species: the need for a flexible asymmetrical approach. Ecological Monographs 67:345-366.

Ecoregions Working Group. 1989. Ecoclimatic regions of Canada. First approximation. Ecoregions working group of the Canada committee on ecological land classification. ELC Series, No. 23. Sustainable Development Branch, Canadian Wildlife Service, Conservation and Protection, Environment Canada, Ottawa, Ontario, Canada.

Ellenberg, H. 1988. Vegetation ecology of Central Europe. Fourth edition, English translation. Translated by Gordon K. Strutt. Cambridge University Press, London, UK.

Ellis, E. C., and N. Ramankutty. 2008. Putting people in the map: anthropogenic biomes of the world. Frontiers in Ecology and the Environment 6:439-447.

Eswaran, H., T. Rice, R. Ahrens, and B. A. Stewart. 2003. Soil classification: a global desk reference. CRC Press, New York, New York, USA.

Faber-Langendoen, D., and C. Josse. 2010. World grasslands and biodiversity patterns. NatureServe, Arlington, Virginia, USA.

Faber-Langendoen, D., et al. 2012. Classification and description of world formation types. Part I (Introduction) and Part II (Description of formation types). Hierarchy Revisions Working Group, Federal Geographic Data Committee, FGDC Secretariat, U.S. Geological Survey, Reston, Virginia, and NatureServe, Arlington, Virginia, USA.

Faber-Langendoen, D., D. L. Tart, and R. H. Crawford. 2009. Contours of the revised U.S. National Vegetation Classification standard. Bulletin of the Ecological Society of America 90:87-93.

FGDC (Federal Geographic Data Committee). 2008. National Vegetation Classification standard, version 2. FGDC-STD005-2008. Vegetation Subcommittee, U.S. Geological Survey, Reston, Virginia, USA.

FGDC (Federal Geographic Data Committee). 2012. Coastal and marine ecological classification standard, version 4.0. FGDCSTD-018-2012. Marine and Coastal Spatial Data Subcommittee, U.S. Geological Survey, Reston, Virginia, USA. 
Flinn, K. M., and P. L. Marks. 2007. Agricultural legacies in forest environments: tree communities, soil properties, and light availability. Ecological Applications 17:452-463.

Franklin, S., D. Faber-Langendoen, M. Jennings, T. KeelerWolf, O. Loucks, A. McKerrow, R. K. Peet, and D. Roberts. 2012. Building the United States National Vegetation Classification. Annali di Botanica 2:1-9.

Frelich, L. E. 2002. Forest dynamics and disturbance regimes: studies from temperate evergreen-deciduous forests. Cambridge studies in ecology. Cambridge University Press, New York, New York, USA.

Fry, J., G. Xian, S. Jin, J. Dewitz, C. Homer, L. Yang, C. Barnes, N. Herold, and J. Wickham. 2011. Completion of the 2006 national land cover database for the conterminous United States. Photogrammetric Engineering and Remote Sensing 77:858-864.

Gabriel, H. W., and S. S. Talbot. 1984. Glossary of landscape and vegetation ecology for Alaska. Alaska Technical Report 10. Bureau of Land Management, U.S. Department of the Interior, Washington, D.C., USA.

Gillison, A. N. 2013. Plant functional types and traits at the community, ecosystem and world level. Pages 347-386 in E. van der Maarel and J. Franklin, editors. Vegetation ecology. Second edition. Wiley-Blackwell, New York, New York, USA.

Gitay, H., and I. R. Noble. 1997. What are functional types and how should we seek them? Pages 3-20 in T. M. Smith, H. H. Shugart, and F. I. Woodward, editors. Plant functional types: their relevance to ecosystem properties and global change. International geosphere-biosphere programme book series. Cambridge University Press, New York, New York, USA.

Greller, A. 2000. Vegetation in the floristic regions of North and Central America. Pages 39-87 in D. Lentz, editor. Imperfect balance, landscapes transformation in Precolumbian Americas. Columbia University Press, New York, New York, USA.

Grime, J. P. 2001. Plant strategies, vegetation processes, and ecosystem properties. Second edition. J. Wiley and Sons, New York, New York, USA.

Grossman, D. H., et al. 1998. International classification of ecological communities: terrestrial vegetation of the United States. Volume I. The National Vegetation Classification system: development, status, and applications. The Nature Conservancy, Arlington, Virginia, USA.

Hadač, E. 1967. On the highest units in the system of plant communities. Folia Geobotanica and Phytotaxonomica 2:429-432.

Higgins, J. V., M. T. Bryer, M. L. Khoury, and T. W. Fitzhugh. 2005. A freshwater classification approach for biodiversity conservation. Conservation Biology 19:432-445.

Hoagland, B. 2000. The vegetation of Oklahoma: a classification for landscape mapping and conservation planning. Southwestern Naturalist 45:385-420.

Hobbs, R. J., et al. 2006. Novel ecosystems: theoretical and management aspects of the new ecological world order. Global Ecology and Biogeography 15:1-7.

Holdridge, L. R. 1947. Determination of world plant formations from simple climatic data. Science 105:367-368.

Huber, O., and R. Riina. 2003. Glosario Fitoecológico de las Américas. Volume 2. Mexico, America Central ye Islas del Caribe: países hispanoparlantes. UNESCO, Paris, France.

Hunter, M. L., G. L. Jacobson, Jr., and T. Webb III. 1988. Paleoecology and the coarse-filter approach to maintaining biological diversity. Conservation Biology 2:375-385.

Jennings, M. D., D. Faber-Langendoen, O. L. Loucks, R. K. Peet, and D. Roberts. 2009. Standards for associations and alliances of the U.S. National Vegetation Classification. Ecological Monographs 79:173-199.

Josse, C., F. Cuesta, G. Navarro, V. Barrena, E. Cabrera, E. Chacón-Moreno, W. Ferreira, M. Peralvo, J. Saito, and A. Tovar. 2009. Ecosistemas de los Andes del Norte y Centro
(Bolivia, Colombia, Ecuador, Perú y Venezuela) Mapa y Memoria Técnica. Secretaría General de la Comunidad Andina, Programa Regional ECOBONA, CONDESANProyecto Páramo Andino, NatureServe, LTA-UNALM, IAvH, ICAE-ULA, CDC-UNALM, Rumbol SRL, Lima, Peru. http://www.comunidadandina.org/public/libro_92.htm Josse, C., et al. 2003. Ecological systems of Latin America and the Caribbean: a working classification of terrestrial systems. NatureServe, Arlington, Virginia, USA.

Keene, R. E., P. F. Hessburg, P. B. Landres, and F. J. Swanson. 2009. The use of historical range of variability (HRV) in landscape management. Forest Ecology and Management 258:1025-1037.

Keith, D. A., et al. 2013. Scientific foundations for an IUCN red list of ecosystems. PLoS ONE 8(5):e62111.

Kent, M. 2012. Vegetation description and analysis: a practical approach. John Wiley and Sons, Hoboken, New Jersey, USA.

Küchler, A. W. 1964. Manual to accompany the map: potential natural vegetation of the conterminous United States. Special publication 36. American Geographical Society, New York, New York, USA.

Küchler, A. W. 1969. Natural and cultural vegetation. Professional Geographer 21:383-385.

Ladle, R. J., and R. J. Whittaker. 2011. Conservation biogeography. Blackwell Publishing, Hoboken, New Jersey, USA.

Leemans, R. 1997. The use of plant functional type classifications to model global land cover and simulate the interactions between the terrestrial biosphere and the atmosphere. Pages 289-316 in T. M. Smith, H. H. Shugart, and F. I. Woodward, editors. Plant functional types: their relevance to ecosystem properties and global change. Cambridge University Press, New York, New York, USA.

Leu, M., S. E. Hanser, and S. T. Knick. 2008. The human footprint in the West: a large-scale analysis of anthropogenic impacts. Ecological Applications 18:1119-1139.

Lincoln, R., G. Boxshall, and P. Clark. 1998. A dictionary of ecology, evolution and systematics. Cambridge University Press, New York, New York, USA.

Loidi, J., and F. Fernández-González. 2012. Potential natural vegetation: reburying or reboring? Journal of Vegetation Science 23:564-604.

Loveland, T. R., J. W. Merchant, D. O. Ohlen, and J. F. Brown. 1991. Development of a land-cover characteristics database for the conterminous U.S. Photogrammetric Engineering and Remote Sensing 57:1453-1463.

Loveland, T. R., B. C. Reed, J. F. Brown, D. O. Ohlen, Z. Zhu, L. Yang, and J. W. Merchant. 2000. Development of a global land cover characteristics database and IGBP DISCover from $1 \mathrm{~km}$ AVHRR data. International Journal of Remote Sensing 21:1303-1330.

Lowry, J., et al. 2007. Mapping moderate-scale land-cover over very large geographic areas within a collaborative framework: A case study of the Southwest Regional Gap Analysis Project (SWReGAP). Remote Sensing of Environment 108:59-73.

Meidinger, D., W. MacKenzie, K. Klinka, and J. Pojar. 2003. A synopsis of vegetation classes, orders and suborders of British Columbia (draft). British Columbia Ministry of Forestry, Victoria, British Columbia, Canada.

Mentis, M. T. 1988. Hypothetico-deductive and inductive approaches in ecology. Functional Ecology 2:5-14.

Metzger, M. J., R. G. H. Bunce, R. H. G. Jongman, R. Sayre, A. Trabucco, and R. Zomer. 2012. A high-resolution bioclimate map of the world: a unifying framework for global biodiversity research and monitoring. Global Ecology and Biogeography 22:630-638.

Miles, L., A. Newton, R. DeFries, C. Ravilious, I. May, S. Blyth, V. Kapos, and J. E. Gordon. 2006. A global overview 
of the conservation status of tropical dry forests. Journal of Biogeography 33:491-505.

Mitchell, F. J. G. 2005. How open were European primeval forests? Hypothesis testing using palaeoecological data. Journal of Ecology 93:168-177.

Mucina, L. 1997. Conspectus of classes of European vegetation. Folia Geobotanica 32:117-172.

Mucina, L., and M. C. Rutherford. 2006. The vegetation of South Africa, Lesotho and Swaziland. Strelitzia 19, South African National Biodiversity Institute, Pretoria, South Africa.

Mueller-Dombois, D., and H. Ellenberg. 1974. Aims and methods of vegetation ecology. John Wiley and Sons, New York, New York, USA.

Navarro, G. 2011. Clasificación de la Vegetación de Bolivia. Centro de Ecología Difusión Simón I. Patiño, Santa Cruz, Bolivia.

NLWRA (National Land and Water Resources Audit). 2001. Australian native vegetation assessment 2001. National Land and Water Resources Audit. Canberra, Australia.

Olson, D. M., et al. 2001. Terrestrial ecoregions of the world: a new map of life on earth. Bioscience 51:933-938.

Otýpková, Z., and M. Chytrý. 2006. Effects of plot size on the ordination of vegetation samples. Journal of Vegetation Science 17:465-472.

Peet, R. K. 2000. Forest and meadows of the Rocky Mountains. Pages 75-122 in M. G. Barbour and W. D. Billings, editors. North American terrestrial vegetation. Second edition. Cambridge University Press, New York, New York, USA.

Peet, R. K. 2008. A decade of effort by the ESA Vegetation Panel leads to a new federal standard. Bulletin of the Ecological Society of America 89:210-211.

Peet, R. K., M. T. Lee, M. D. Jennings, and D. FaberLangendoen. 2012. VegBank: a permanent, open-access archive for vegetation plot data. Biodiversity and Ecology 4:233-241.

Peet, R. K., and D. W. Roberts. 2013. Classification of natural and semi-natural vegetation. Pages 28-70 in J. Franklin and E. van der Maarel, editors. Vegetation ecology. Second edition. Oxford University Press, New York, New York, USA.

Peet, R. K., T. R. Wentworth, and P. S. White. 1998. The North Carolina vegetation survey protocol: a flexible, multipurpose method for recording vegetation composition and structure. Castanea 63:262-274.

Peinado, M., F. Alcaraz, J. L. Aguirre, and J. M. MartínezParras. 1997. Vegetation formations and associations of the zonobiomes along the North American Pacific Coast: from Northern California to Alaska. Plant Ecology 129:29-47.

Peinado, M., F. M. Ocaña-Peinado, J. L. Aguirre, J. Delgadillo, M. Á. Marcías, and G. Díaz-Santiago. 2011. A phytosociological and phytogeographical survey of the coastal vegetation of western North America: beach and dune vegetation from Baja California to Alaska. Applied Vegetation Science 14:464-484.

Pignatti, S., E. Oberdorfer, J. H. J. Schaminée, and V. Westhoff. 1994. On the concept of vegetation class in phytosociology. Journal of Vegetation Science 6:143-152.

Pojar, J., K. Klinka, and D. V. Meidinger. 1987. Biogeoclimatic ecosystem classification in British Columbia. Forest Ecology and Management 22:119-154.

Raunkiær, C. 1934. The life forms of plants and statistical plant geography. Clarendon Press, Oxford, UK.

Richards, P. W. 1952. The tropical rain forest: an ecological study. Cambridge University Press, New York, New York, USA.

Rivas-Martínez, S. 1996-2010. Sistema de Clasificación Bioclimática Mundial. Centro de Investigaciones Fitosociológi- cas, Madrid, Spain. www.ucm.es/info/cif/book/bioc/global_ bioclimatics-2008_00.htm

Rivas-Martínez, S. 1997. Syntaxonomical synopsis of the potential natural plant communities of North America, I. Itinera Geobotanica 10:5-148.

Rivas- Martínez, S., G. Navarro, A. Penas, and M. Costa. 2011. Biogeographic map of South America. A preliminary survey. International Journal of Geobotanical Research 1:21-40.

Rivas-Martínez, S., D. Sánchez-Mata, and M. Costa. 1999. North American boreal and western temperate forest vegetation. Syntaxonomical synopsis of the potential natural plant communities of North America, II. Itinera Geobotanica 12:5-316.

Rodríguez, J. P., et al. 2011. Establishing IUCN red list criteria for threatened ecosystems. Conservation Biology 25:21-29.

Rodwell, J. S. 1991-2000. British plant communities. Volumes 1-5. Cambridge University Press, New York, New York, USA.

Rodwell, J. S., J. H. J. Schamineé, L. Mucina, S. Pignatti, J. Dring, and D. Moss. 2002. The diversity of European vegetation. An overview of phytosociological alliances and their relationships to EUNIS habitats. Report EC-LNV nr. 2002/054. EC-LNV, Wageningen, The Netherlands.

Roleček, J., L. Tichý, D. Zelený, and M. Chytrý. 2009. Modified TWINSPAN classification in which the hierarchy respects cluster heterogeneity. Journal of Vegetation Science 20:596-602.

Rowe, J. S., and B. V. Barnes. 1994. Geo-ecosystems and bioecosystems. Bulletin of the Ecological Society of America 75:40-41.

Rutherford, M. C., L. Mucina, and L. W. Powrie. 2006. Biomes and bioregions of southern Africa. Pages 30-51 in L. Mucina and M. C. Rutherford, editors. The vegetation of South Africa, Lesotho and Swaziland. Strelitzia 19, South Africa National Biodiversity Institute, Pretoria, South Africa.

Sawyer, J. O., T. Keeler-Wolf, and J. M. Evens. 2009. A manual of California vegetation, Second edition. California Native Plant Society, Sacramento, California, USA.

Sayre, R., J. Bow, C. Josse, L. Sotomayor, and J. Touval. 2008. Terrestrial ecosystems of South America. Pages 131-152 in J. C. Campbell, K. B. Jones, and J. H. Smith, editors. North America land cover summit - a special issue of the association of american geographers. U.S. Geological Survey, Reston, Virginia, USA.

Sayre, R., P. Comer, J. Hak, et al. 2013. A new map of standardized terrestrial ecosystems of Africa. Association of American Geographers, Washington, D.C., USA.

Schultz, J. 1995. The ecozones of the world. Springer-Verlag, New York, New York, USA.

Scott, J. M., P. J. Heglund, M. L. Morrison, J. B. Haufler, M. G. Raphael, W. A. Wall, and F. B. Samson. 2002. Predicting species occurrences: issues of accuracy and scale. Islands Press, Washington, D.C., USA.

Shimwell, D. W. 1971. The description and classification of vegetation. University of Washington Press, Seattle, Washington, USA.

Specht, R. L., E. M. Roe, and V. H. Boughton. 1974. Conservation of major plant communities in Australia and Papua New Guinea. Australian Journal of Botany Supplemental Series 4:1-667.

Specht, R. L., and A. Specht. 2001. Ecosystems of Australia. Pages 307-324 in S. Levin, editor. Encyclopedia of Biodiversity. Volume 1. Academic Press, New York, New York, USA.

Spribille, T. 2002. The mountain forests of British Columbia and the American Northwest: floristic patterns and syntaxonomy. Folia Geobotanica 37:475-508.

Stoddard, J. L., D. P. Larsen, C. P. Hawkins, R. K. Johnson, and R. H. Norris. 2006. Setting expectation for the ecological condition of streams: the concept of reference condition. Ecological Applications 16:1267-1276. 
Strong, W. L., E. T. Oswald, and D. J. Downing. 1990. The Canadian vegetation classification system, first approximation. Ecological land classification series, No. 25. National Vegetation Working Group, Canadian Committee on Ecological Land Classification. Sustainable Development, Corporate Policy Group, Environment Canada, Ontario, Ottawa, Canada.

Sukumar, R., and P. S. Easa. 2006. Elephant conservation in south India: issues and recommendations. Gajah 25:71-86.

Swetnam, T. W., C. D. Allen, and J. L. Betancourt. 1999. Applied historical ecology: using the past to manage for the future. Ecological Applications 9:1189-1206.

Takhtajan, A. 1986. Floristic regions of the world. University of California Press, Berkeley, California, USA.

Talbot, S. S., S. L. Talbot, and F. J. A. Daniëls. 2005. Comparative phytosociological investigation of subalpine alder thickets in southwestern Alaska and the North Pacific. Phytocoenologia 35:727-759.

Tart, D., C. K. Williams, C. K. Brewer, J. P. DiBenedetto, and B. Schwind. 2005. Section 1: existing vegetation classification and mapping framework. Pages 1-39 in R. Brohman and L. Bryant, editors. 2005. Existing vegetation classification and mapping technical guide. General technical report WO-67. U.S. Department of Agriculture Forest Service, Washington, D.C., USA.

Thompson, I. D., M. R. Guariguata, K. Okabe, C. Bahamondez, R. Nasi, V. Heymell, and C. Sabogal. 2013. An operational framework for defining and monitoring forest degradation. Ecology and Society 18:20.

Thornthwaite, C. W. 1948. An approach toward a rational classification of climate. Geographical Review 38:55-94.

Tichý, L., M. Chytrý, M. Hájek, S. S. Talbot, and Z. BottaDukát. 2010. OptimClass: using species-to-cluster fidelity to determine the optimal partition in classification of ecological communities. Journal of Vegetation Science 21:287-299.

Tierney, G. L., D. Faber-Langendoen, B. R. Mitchell. G. Shriver, and J. Gibbs. 2009. Monitoring and evaluating the ecological integrity of forest ecosystems. Frontiers in Ecology and the Environment 7:308-316.

Tiner, R. W. 2006. Lists of potential hydrophytes for the United States: a regional review and their use in wetland identification. Wetlands 26:624-634.

UNESCO (United Nations Educational, Scientific, and Cultural Organization). 1973. International classification and mapping of vegetation. Series 6. Ecology and conservation. United Nations, Paris, France.

USDA (U.S. Department of Agriculture). 1999. Soil taxonomy. Agricultural handbook number 436. USDA, Natural Resources Conservation Service, Washington, D.C., USA.

van der Maarel, E. 2005. Vegetation ecology: an overview. Pages 1-51 in E. van der Maarel, editor. Vegetation ecology. Blackwell Publishing, Boston, Massachusetts, USA.

Veldman, J. W., and F. E. Putz. 2011. Grass-dominated vegetation, not species-diverse natural savanna, replaces degraded tropical forests on the southern edge of the Amazon Basin. Biological Conservation 144:1419-1429.

Walker, M. D., F. J. A. Daniëls, and E. van der Maarel. 1994. Circumpolar arctic vegetation: introduction and perspectives. Journal of Vegetation Science 5:757-764.
Walter, H. 1985. Vegetation of the Earth, and ecological systems of the geobiosphere. Third edition. Springer-Verlag, New York, New York, USA.

Wang, G., G. Zhou, L. Yang, and Z. Li. 2003. Distribution, species diversity and life-form spectra of plant communities along an altitudinal gradient in the northern slopes of Qilianshan Mountains, Gansu, China. Plant Ecology 165:169-181.

Warming, E. 1909. Oecology of plants: an introduction to the study of plant communities. Clarendon Press, Oxford, UK.

Webb, L. J., J. G. Tracey, W. T. Williams, and G. N. Lance. 1970. Studies in the numerical analysis of complex rain forest communities. V. A comparison of the properties of floristic and physiognomic-structural data. Journal of Ecology 58:203-232.

Wells, E. D. 1996. Classification of peatland vegetation in Atlantic Canada. Journal of Vegetation Science 7:847-878.

Werger, M. J. A., and J. T. C. Sprangers. 1982. Comparison of floristic and structural classification of vegetation. Vegetatio 50:175-183.

Westhoff, V. 1967. Problems and use of structure in the classification of vegetation. The diagnostic evaluation of structure in the Braun-Blanquet system. Acta Botanica Neerlandica 15:495-511.

Westhoff, V., and E. van der Maarel. 1973. The BraunBlanquet approach. Pages 617-726 in R. H. Whittaker, editor. Handbook of vegetation science. Part V. Ordination and classification of communities. Springer, The Hague, The Netherlands.

White, F. 1983. The vegetation of Africa. UNESCO, Paris, France.

Whitmore, T. C. 1984. Tropical rain forests of the Far East. Second edition. Clarendon Press, Oxford, UK.

Whittaker, R. H. 1962. Classification of natural communities. Botanical Review 28:1-239.

Whittaker, R. H. 1975. Communities and ecosystems. Second edition. MacMillan, New York, New York, USA.

Williams, J. W., T. Webb III, P. H. Richard, and P. Newby. 2000. Late quaternary biomes of Canada and the eastern United States. Journal of Biogeography 27:585-607.

Williams, M. A., and W. L. Baker. 2011. Testing the accuracy of new methods for reconstructing historical structure of forest landscape using GLO survey data. Ecological Monographs 81:63-88.

Willis, K. J., and H. J. B. Birks. 2006. What is natural? The need for a long-term perspective in biodiversity conservation. Science 314:1261-1265.

Willner, W. 2006. The association concept revisited. Phytocoenologia 36:67-76.

Wright, J. P., and J. D. Fridley. 2010. Biogeographic synthesis of secondary succession rates in eastern North America. Journal of Biogeography 37:1584-1596.

Zanini, K. J., R. S. Bergamin, R. E. Machado, V. D. Pillar, and S. C. Müller. 2014. Atlantic rain forest recovery: successional drivers of floristic and structural patterns of secondary forest in Southern Brazil. Journal of Vegetation Science 25(4):1056-1068.

\section{Supplemental Material}

\section{Ecological Archives}

Appendices A-E are available online: http://dx.doi.org/10.1890/13-2334.1.sm 
Don Faber-Langendoen, Todd Keeler-Wolf, Del Meidinger, Dave Tart, Bruce Hoagland, Carmen Josse, Gonzalo Navarro, Serguei Ponomarenko, Jean-Pierre Saucier, Alan Weakley, and Patrick Comer. 2014. EcoVeg: a new approach to vegetation description and classification. Ecological Monographs 84:533-561.

\section{Erratum:}

A sentence was omitted from the end of the first paragraph on Nomenclature rules on p. 551. It should read:

"All first letters of english words in a vegetation type name are capitalized, and separated, as needed, by either a hyphen, with spaces ( - ), a comma and space (, ) or the "and" symbol with spaces ( \& )."

These rules should be applied to Tables 1, 2, 5, and 6, and Appendix C, and wherever formal vegetation type names are used in the text. E.g. Table 1. "Forest and Woodland "should be "Forest \& Woodland", etc. 